\title{
EL GÉNERO LITERARIO GASTRONÓMICO EN GRAN BRETAÑA EN LA PRIMERA MITAD DEL SIGLO XIX
}

\author{
THE GASTRONOMIC GENRE IN GREAT BRITAIN \\ IN THE FIRST HALF OF THE $19^{\mathrm{TH}}$ CENTURY
}

José María Díaz Rodríguez

Entregado el 18-7-2012 y aceptado el 3-11-2012.

Resumen: Dentro de la literatura británica dedicada a la alimentación y a la cocina, sólo se habían encontrado algunos ejemplos de carácter gastronómico en tratados de cocina como The Cook's Oracle, del doctor William Kitchiner, y algunos retazos hallados en otras obras culinarias. Sin embargo, a lo largo de la primera mitad del siglo XIX, se puede constatar la existencia de una serie de autores que, fuertemente influidos por autores de la literatura gastronómica francesa, especialmente Grimod de la Reynière, desarrollaron un género específicamente gastronómico. Fruto del nuevo espíritu romántico, los gastrónomos británicos fueron capaces de dotar a sus escritos de un estilo diferenciado; exhibiendo, por ejemplo, un humorismo desenfadado e iconoclasta que contrastaba con un rigorismo moral, mostrando asimismo una peculiar complacencia hacia el maltrato a los animales o una entrega incondicional a los placeres de los sentidos.

Palabras clave: gastronomía, alimentación, cocina, tratado, literatura.

\footnotetext{
Abstract: Within the British literature dedicated to food and cookery, only some gastronomic examples had been found in cookery treatises such The Cook's Oracle, by Dr. William Kitchiner as well as some snippets included in other culinary works. However, throughout the first half of the 19th century, the existence of a group of authors can be identified who, strongly influenced by French gastronomic writers, especially, Grimod de la Reynière, are responsible
} 
for the development of a genre which was specifically gastronomic. Following the new spirit of Romanticism, the British gastronomes were able to provide their works with a distinct style; exhibiting, for instance, a kind of uninhibited humour, which was in contrast with moral rigorousness, showing at the same time a peculiar complacency to animal cruelty or an unconditional indulgence in the pleasures of the senses.

Key words: gastronomy, food, cookery, treatise, literature. 
Los autores de uno de los grandes clásicos de la historia de la alimentación británica - The Englisman's Food-Drummond y Wilbraham destacaban con acierto el componente gastronómico de la obra de William Kitchiner, The Cook's Oracle; sin duda uno de los libros de cocina más difundidos en el Reino Unido y la América anglosajona desde principios del siglo XIX. No habían advertido, sin embargo, la importante contribución de un reducido grupo de escritores británicos al desarrollo de la literatura gastronómica con posterioridad a 1817 , fecha de la primera edición del repertorio de Kitchiner y a lo largo de toda la primera mitad del siglo XIX. ${ }^{1}$

Por otra parte, según Stephen Mennel, ya habían existido discusiones de carácter gastronómico en los prólogos o prefacios de las obras culinarias. El gastrónomo como figura distintiva y reconocible, sin embargo, surgió en realidad después de la Revolución Francesa. Denise Gigante ahonda más en esta cuestión y explica cómo los grandes chefs franceses, viéndose obligados a emigrar tras los acontecimientos de la revolución, fueron trasladados del ámbito privado al público; ayudando así a promocionar el nuevo y complejo mundo de la comida ofertada desde el restaurante. Este establecimiento, al contrario que la table d'hôte francesa o la inn inglesa, en la que los comensales consumían una comida preparada por un anfitrión, proporcionaba a la clientela la oportunidad de expresar sus gustos individuales mediante la elección entre una variedad de platos presentados en un «menú». 2

1 «Es significativo el hecho de que la literatura inglesa del siglo diecinueve no haya producido una obra en manera alguna comparable al clásico de Brillat-Savarin, Physiology du Goût, que llegó a ser tan popular y se editó varias veces. Quizás, lo más parecido a esta obra sea The Cook's Oracle, escrita por el polifacético y ligeramente excéntrico doctor Kitchiner». Drummond, J. C., and Wilbraham, The Englishman's Food, A History of Five Centuries of English Diet, Jonathan Cape, London, 1969, pp. 334 y 335.

2 «1837, del Fr. menu de repas "lista de lo que se sirve en una comida", del Fr. M. menu (adj.) "pequeño, detallado", del L. minutus "pequeño", lit. "hecho más pequeño", part. de minuere "disminuir", de la raíz de minus». Online Etimology Dictionary. http://www. etymonline.com [Con acceso el quince de febrero de 2010]. Sobre el surgimiento del restaurante como establecimiento público y su contribución al arte gastronómico es fundamental la obra de John Burnett, England Eats out. 1830 - Present. En este trabajo, se constata el origen francés del restaurante: «Hacia 1830, existía una jerarquía de establecimientos de comidas... lo que se echaba en gran falta en aquel tiempo era el restaurante, todavía en un estadio temprano de su desarrollo, aunque destinado a convertirse en el tipo predominante de hostelería. Los orígenes, las fechas, los fundadores y la terminología son todos objeto de gran disputa. Sin embargo, existe acuerdo en el hecho de que los restauran- 
El término «menú», sin embargo, cobró un nuevo significado en los primeros restaurantes franceses como algo intimidatorio, incluso épico en su ámbito. Los comensales se vieron repentinamente en una nueva situación que les obligaba a demostrar su cultura gastronómica ante la sociedad europea del buen gusto. ${ }^{3}$

Esta diseminación de la cocina de las altas capas sociales que los gastrónomos realizaron entre el gran público burgués, en parte, contribuyó también a mantener los códigos elitistas del antiguo régimen. Sin embargo, y paradójicamente, la publicación de estas reglas del gusto cumplió también una función democratizadora al proporcionar a los nuevos ricos el acceso a un ámbito de distinción cultural que, previamente, había pertenecido exclusivamente a la nobleza y a la aristocracia. ${ }^{4}$

La emigración de los grandes chefs franceses a Londres, principalmente, ejerciendo su arte en los nuevos establecimientos públicos de comidas, estableció nuevos parámetros del gusto, y cuando los gastrónomos expresaron de forma literaria los placeres de la mesa, surgió un nuevo género literario, el género gastronómico. ${ }^{5}$

tes aparecieron en París y en que un "restaurant" empezó a servir un reconfortante bouillon (una sopa hecha a base de extractos de carne, pollo y cebada), que se creía que devolvía la salud, mejorando las digestiones ligeras y los estados nerviosos». John Burnett, England Eats out. 1830 - Present, Pearson Education Limited, Harlow, 2004, p. 9. Otro trabajo fundamental sobre la aparición de los restaurantes es la obra de Rebecca L. Spang, The Invention of the Restaurant. Paris and Modern Gastronomic Culture, Harvard University Press, Cambridge, 2001.

${ }^{3}$ Gigante, Denise, Gusto. Essential Writings in Nineteenth-Century Gastronomy, Routledge (New York, 2005), xvii-xviii.

${ }^{4}$ Stephen Mennell corrobora la existencia de esta función democratizadora pero le añade una dimensión literaria: «Argumentaré que los gastrónomos, lo hayan deseado o no, han cumplido una función en la conformación del gusto. Los textos gastronómicos, al igual que todo tipo de libros, cumplen esta función porque, desde el momento en que son imprimidos, diseminan un conocimiento de estándares de élite más allá de las élites. Evidentemente, los autores y editores buscan las recompensas económicas fuera de los círculos más exclusivos. Ambas funciones, de estándares articuladores y de gusto democratizador, siempre coexisten en gastronomía, aunque el equilibrio existente entre ambos se haya descompensado en los dos últimos siglos». Mennell, Stephen, All Manners of Food. Eating and Taste in England and France from the Middle Ages to the Present, Basil Blackwell (Oxford, 1985), p. 266.

5 «La capital culinaria del mundo en aquellos años era París. Sin embargo, cuando muchos chefs profesionales emigraron a Londres estableciendo nuevos espacios de comidas discrecionales en tabernas, clubes y hoteles su influencia se extendió. Los profesionales del gusto en los dos núcleos cosmopolitas de Europa (el París posrevolucionario y el Londres del principio de la Regencia) transformaron el propio concepto del gusto 
Antes de continuar examinando el género, sin embargo, es preciso definir la constelación de términos comprendidos en el campo semántico de la gastronomía. El vocablo «gastronomie» fue, según Mennell, utilizado por primera vez por Joseph Berchoux en su poema, La Gastronomie, en 1801 y se utilizó rápidamente en Francia e Inglaterra para designar el arte y la ciencia de la comida exquisita. ${ }^{6}$ Stephen Mennell proporciona una detallada información de los términos derivados del sustantivo «gastronomy»:

«Gastronome», en este sentido, fue una derivación de «gastronomy», y los términos «gastronomer» y «gastronomist» se utilizaron durante el siglo XIX en Inglaterra para designar a «un árbitro de la buena comida». Las connotaciones de «gastronome», en parte, se solapan con las de las expresiones antiguas «Epicure» y «gourmand», que tenían significados peyorativos próximos al de glotón, «alguien que come en exceso, con gula», mientras que «epicure» había adquirido a principios del siglo XIX, especialmente en Inglaterra, un significado más favorable como «alguien que cultiva un gusto refinado por los placeres de la mesa».

En Francia, el término «gourmand» había adquirido este mismo significado favorable y, en tal sentido, fue utilizado por Grimod de la Reynière el título de su Almanach des Gourmands y, precisamente, el Oxford English Dictionary también registra «gourmand» con ese mismo sentido favorable a principios del siglo XIX, aunque en la actualidad, al igual que ocurre en Francia, los escritores establecen una distinción entre «gourmand», con el sentido peyorativo de glotón, y «gourmet», con el significado de «persona que posee un paladar refinado».

Al final de esta argumentación terminológica, Stephen Mennell aporta su propia distinción que resulta muy clarificadora, puesto que incorpora un aspecto literario, que es indispensable en este trabajo, al precisar el sentido que se le da al gastrónomo («gastronome»). Éste, al contrario que el gourmet, no sólo cultiva el gusto refinado y los placeres de

estático, pasando de ser una desinteresada apreciación de las bellas artes a convertirse en un conjunto de prácticas materiales para aquellos consumidores que perseguían una distinción social. Los gastrónomos dirigieron esta transición por medio de un nuevo género literario consistente en textos sobre la comida que anteriormente había sido el hermano pobre de las artes». Gigante, Denise, Gusto. Essential Writings in Nineteenth-Century Gastronomy, xviii, xix.

${ }^{6}$ Véase Spang, Rebecca L., The Invention of the Restaurant, p. 146. 
la mesa, sino que escribe sobre ellos, es un teórico y propagandista del gusto culinario. ${ }^{7}$

\section{Las características de una nueva literatura gastronómica}

Los gastrónomos románticos, en realidad, incluyeron el apetito en una nueva concepción estética identificando tres variedades en su formulación: el hambre más básica, el deseo provocado por un plato apetitoso y, finalmente, un apetito estimulado por todas las artes de la cocina una vez que el hambre había sido satisfecha. Es, precisamente, en este último tipo de apetito en el que se concentra el interés del gastrónomo, el relativo al apetito artificial o cultivado, el más alejado de la necesidad primaria o biológica. ${ }^{8}$

${ }^{7}$ En la obra Tabella Cibaria, de Ange Denis Macquin, se especifica aún más la definición y se establecen las siguientes distinciones: «Encontramos que existen curiosos matices entre las denominaciones francesas gourmand y gourmet. En el idioma de esa nación, tan famosa por relajarse en la adoración de Comus, la palabra gourmand significa, como hemos afirmado antes, un hombre que, al haber tenido la oportunidad de estudiar los diferentes sabores de varios alimentos, selecciona el mejor, el más placentero para el paladar. Su carácter está originado en la práctica y responde al nombre de epicure, en el pleno sentido de la palabra como se usa en inglés. Por otra parte, el gourmet considera el aspecto teórico de la Gastronomía; especula más que practica y se enorgullece eminentemente al discernir los más placenteros grados y los matices más evanescentes de bondad y perfección en las cuestiones que se le proponen. De hecho, la palabra gourmet se ha venido utilizando durante mucho tiempo para designar a aquel hombre que al tomar un sorbo de la copa de plata del viticultor puede afirmar inmediatamente de qué país procede el vino, además de su edad. Esta denominación ha adquirido últimamente un alto grado de significado, y no inmerecidamente, ya que expresa lo que las otras dos palabras no pueden expresar. De las anteriores observaciones podemos concluir que el glutton practica sin prestar atención a la teoría y entonces lo denominamos gastrophile. El gourmand une teoría y práctica y se le puede denominar gastronomer. El gourmet es meramente teórico, le importa poco la práctica y merece la más alta denominación de gastronomer. Macquin, Ange Denis, Tabella Cibaria. The Bill of Fare. Latin Poem, Richmond, Nelly and Jones (London, 1820), pp. 15, 16.

${ }^{8}$ Para Denise Gigante, el gusto es un término de estética del romanticismo utilizado por Lord Byron, Leigh Hunt, John Keats y otros, elaborado con más profundidad por William Hazlitt, en 1816, en su ensayo On Gusto: «El gusto en el arte es el poder o la pasión que define cualquier objeto». A continuación añadía ejemplos de la pintura de Tiziano, Rubens, Albano, Vandyke, Miguel Angel, Correggio, Rembrant y Rafael, entre otros y también en las obras de Shakespeare, Milton, Dryden, Boccacio y Rabelais. Véase, Hazlitt, William, A Collection of Essays on Literature, Men and Manners, Archibald, Constable \& Company, (London, 1817), p.20 y ss. Véase asimismo, Gigante, Denise, Gusto. Essential Writings in Nineteenth-Century Gastronomy, xiii. 
Ahora bien, la literatura gastronómica desarrollada en primer lugar en Francia, y posteriormente imitada en gran medida en Inglaterra, exhibe una serie de características o componentes que es preciso recordar.

En primer lugar, el desarrollo que adquieren las disquisiciones sobre lo que constituye una buena práctica en la composición de los menús, la secuenciación de los platos y las técnicas de servicio, siendo el arquetipo de este ingrediente la obra Manuel des Amphitryons, de Grimod de la Reynière. En segundo lugar, la existencia de una preocupación dietética que establece qué alimentos y qué formas de cocina son adecuados para cada persona según el conocimiento prevalente en el momento. Un tercer componente, quizás el más importante dentro de la tradición literaria gastronómica, es la historia, el mito y la misma historia sirviendo como mito y colocado todo ello al servicio de la meditación gastronómica. El núcleo más sólido de este aspecto se puede encontrar en biografías de personajes históricos que fueron grandes comensales $\mathrm{y}$, a partir del siglo XIX, de cocineros, entre los que destaca el francés Antonin Carême. También pueden incluirse aquí las numerosas variantes sobre el origen, generalmente poco fundado históricamente, de recetas concretas, de técnicas y de sus nombres, como puede ser el cásico ejemplo de la mayonesa.

Desde al punto de vista de la retórica argumental literaria, en estas historias podía aparecer un personaje importante y también podía incorporarse el elemento del accidente. A principios del siglo XIX, la presencia de un protagonista famoso, que presenciaba el descubrimiento que realizaba un cocinero, expresaba el equilibrio entre el narrador y el propio cocinero. Pero este equilibrio, presente al comienzo de la centuria, cuando comenzaron a escribirse las primeras obras del género gastronómico, se fue decantando poco a poco, significativamente, a favor del cocinero.

Finalmente, el cuarto componente significativo de la literatura gastronómica es la nostálgica evocación de banquetes memorables, o la razón de por qué tal o cual menú había resultado extraordinario; que casi constituye un capítulo aparte dentro este género. ${ }^{9}$

De todos modos la obra literaria gastronómica, según Dense Gigante, es tan omnívora como los propios practicantes gastrónomos, y absorbe una amplia variedad de formas literarias, tales como máximas y reflexiones, meditaciones, relatos o descripciones geograficas, narraciones de via-

9 Vid. «Gastronomy as a Literary Genre» de la obra de Stephen Mennell, All Manners of Food. Eating and Taste in England and France from the Middle Ages to the Present, pp. 270-272. 
jes, intercambios epistolares, poemas, diálogos, sátiras y parábolas basadas en el modelo gastronómico; lo que no deja de ser significativo de la importancia que la cocina está adquiriendo dentro del conjunto de las prácticas culturales y sociales de la época. ${ }^{10}$ En particular, la relación de este inventario temático de la literatura gastronómica con respecto al restaurante se puede apreciar en la visión de Rebecca Spang, para quien el restaurante llegó a ser toda una institución cultural y social. ${ }^{11}$

En cualquiera de los casos, el texto que supone la fundación de la literatura gastronómica fue el Almanach des Gourmands, de Grimod de la Reynière, publicado anualmente entre 1803 y 1811, y que estaba inspirado en el Almanach Royal, que en el París del siglo XVII proporcionaba información sobre los burócratas y otros funcionarios del Estado. El primer ensayo gastronómico de cierto relieve en Gran Bretaña, a su vez, fue un texto anónimo de tono humorístico, pero erudito, The School of Good Living (1814) que hacía una historia de la cocina y de las obras culinarias desde la antigüedad. ${ }^{12}$

${ }^{10}$ Gigante, Denise, Gusto. Essential Writings in Nineteenth-Century Gastronomy, xix.

11 «Intercalando anécdotas sobre comidas consumidas (o perdidas) con insinuaciones útiles, descripciones hiperbólicas, críticas de restaurantes y recetas elaboradas de forma ocasional, el Almanach des gourmands combina las tradiciones clásica y renacentista del simposio con las formas más cada vez más populares de la guía y del almanaque. Dentro de estos textos, y mediante las crecientes codificaciones de la práctica cotidiana que ambos acompañaron y estimularon, el restaurante se convirtió en una auténtica institución cultural y social, un hito fácilmente identificable. Por tanto, al concentrarse exclusivamente en los alimentos y en las comidas, la literatura gastronómica le proporcionó una nueva prominencia al restaurante y pasó de ser un lugar de escándalo a convertirse en un lugar de celebración». Spang, Rebecca L. The Invention of the Restaurant, p. 151.

12 El prefacio de esta obra, escrita en la ciudad de Bath, comienza en un tono hiperbólico alabando la ciencia culinaria: «La observación del surgimiento y progreso de la ciencia alimentaria constituye una parte de la historia no menos curiosa que interesante, siguiendo su rastro desde la edad de las bellotas trituradas hasta los refinamientos del lujo moderno. El resultado de este estudio no puede dejar de imprimir en la mente una verdad evidente y de gran magnitud: el hecho de que la cocina es el origen de todas las artes, es la fuente prolífica cuyos sabrosos arroyos han regado el árbol del conocimiento y lo han nutrido hasta que alcanzó un crecimiento lujurioso. El genio dormitaba en su barro natal, el talento no nacía, ningún hombre vivo avanzaba, ningún Paria de mármol respiraba como un busto animado, la casa de la moneda de la fantasía no acuñaba la moneda de oro ni la imaginación del bardo resplandecía con fuego poético hasta que el campo baldío fue aclamado por los rayos geniales de la refulgencia culinaria». Anonymous, The School of Good Living; or, A Literary and Historical Essay on the European Kitchen, Printed by J. Gillet (London, 1814), pp. 9, 10. 
Denise Gigante, en su excelente introducción a una antología de textos gastronómicos del siglo XIX, divide sus perspectivas dominantes en tres diferentes enfoques, equivalentes a un menú de tres platos. El primer servicio está dedicado al filósofo gastronómico, el segundo se refiere a la cultura gastronómica y el tercero, a la gastronomía como género estrictamente literario. El esquema sirve bien, desde luego, para organizar los principios e ideas subyacentes en la literatura gastronómica de la época; paso previo para analizar más al detalle los trabajos de los autores de gastronomía ingleses que, como se ha afirmado, desarrollaron su actividad literaria inspirándose en los modelos franceses. ${ }^{13}$

Con respecto al componente filosófico de la gastronomía, Gigante asegura que la obsesión por el concepto de gusto fue lo que motivó las primeras formas de literatura gastronómica en francés y en inglés. El llamado «hombre de gusto» era un epicúreo racional, no un glotón que comía sin pensar, impelido por una pura compulsión física.

El «gourmand» de principios del siglo XIX se fundó sobre las connotaciones etimológicas del gusto - sapere, que en latín también significa conocer-. De la misma manera, el poema gastronómico Tabella Cibaria; The Bill of Fare se preocupaba de puntualizar que, mientras que el glotón aparta vergonzosamente todo lo relacionado con el placer racional de crear o estimular el apetito para concentrarse únicamente en la cantidad, ${ }^{14}$ el «gourmand» busca por el contrario la delicadeza y el sabor distintivo de los variados platos presentados para su juicio y discernimiento del paladar. Los gastrónomos románticos incluían el apetito en la estética y la comida, al igual que otros objetos de arte; proporcionando una ocasión para el juicio y ejercicio de las más altas facultades mentales. En este sentido, se comprende mejor que tanto Grimod de la Reynière como su sucesor británico, Launcelot Sturgeon, hablasen de la mostaza o de los almíbares «considerados filosóficamente». Es así como Grimod redefine al «gourmand», enfatizando la importancia que tiene la reflexión mental de quien come. ${ }^{15}$

13 Gigante, Denise, Gusto. Essential Writings in Nineteenth-Century Gastronomy, xix-xlxxx.

${ }^{14}$ Macquin, Ange Dennis, Tabella Cibaria. The Bill of Fare, Sherwood, Neely and Jones (London, 1820)

15 «El gourmand no sólo es aquél que come con profundidad, es decir, con reflexión y sensualidad, aquél que nunca deja nada en el plato ni en el vaso, el que no aflige a su anfitrión con una negativa, ni a su vecino por un exceso de sobriedad: más bien, se suma al más abundante apetito con humor jovial, sin el que la mayoría de las celebraciones no son más que una triste hecatombe. Siempre dispuesto con su plática, mantiene una 
En consecuencia, el «gourmand» romántico persigue conscientemente los placeres mentales a través del gusto físico, secundando la máxima de que un hombre que sabe vivir, come y bebe poco en la mesa. La moderación es, por tanto, una característica central en la gastronomía del siglo XIX, y en general los escritores gastronómicos de esta tradición insisten en la templanza como una de las claves del buen gusto.

Otra cuestión crucial dentro de la postura del hombre de gusto postrevolucionario era su capacidad para transmitir a los otros sus sensaciones mediante la expresión elocuente. Un hombre de gusto no sólo necesitaba captar los principios racionales sobre los que se basaba el propio placer, sino que tenía también que disertar sobre ellos con gracia e ingenio. Este imperativo de la autoexpresión transcendía al escenario de disputa filosófica de la Ilustración y, en el universo gastronómico, se introducía en el arte cotidiano de la conversación. La preocupación por los principios filosóficos, típica del siglo XVIII y tan frecuente en la literatura gastronómica durante la era postrevolucionaria, nos remite a una cuestión más espinosa dentro de la teoría del gusto durante la Ilustración: el hecho de que el gusto individual, aunque subjetivo, debe estar gobernado por ciertas leyes universales. Tales presupuestos, sin embargo, discutían la vieja máxima de que de gustibus non est disputandum, que impediría la posibilidad de deliberación racional a este respecto. ${ }^{16}$

Joseph Addison, uno de los padres fundadores de la estética ilustrada, a pesar de haber comparado el crítico literario con el «connoisseur» de té en su ensayo On Taste, publicado en The Spectator en 1711, estaba preocupado principalmente por la apreciación mental de la belleza. Por el contrario, los gastrónomos románticos buscaban elevar la respetabilidad

continua actividad de los sentidos que la naturaleza le ha proporcionado. Finalmente, su memoria está repleta de anécdotas, cuentos amenos e historias que narra entre plato y plato y en los intersticios de la comida, de tal manera que incluso los más reposados y sobrios participantes disculpen su apetito». Grimod de la Reynière, Almanach des Gourmands, 2: vi-vii, citado en Gigante, Denise, Gusto. Essential Writings in Nineteenth-Century Gastronomy, xx.

${ }^{16}$ Para ilustrar este punto, Denise Gigante comenta el caso del Dr. Johnson, de quien su biógrafo y amigo, Boswell, afirmaba que era un gastrónomo que hablaba de los asuntos del estómago como si se tratase de una cuestión filosófica urgente. Recuérdese su famosa cita sobre la importancia de esta víscera: «En lo que a mí respecta, me preocupo de mi estómago con mucho estudio porque considero que aquél a quien no le preocupa su estómago es muy poco probable que le preocupe cualquier otra cosa». Boswell, James, The Life of Samuel Johnson, Hutchinson (London, 1791), p. 114. Véase asimismo, Gusto. Essential Writings in Nineteenth-Century Gastronomy, xxi. 
filosófica de la lengua, es decir la zona visceral de la boca. Para estos escritores, los «bajos» sentidos del gusto y el olor podrían sujetarse a los mismos principios reguladores de la consciencia y la moralidad que se les supone a las sensaciones reflexivas. Grimod de la Reynière y sus «gourmands», muy lejos de considerar al cocinero como un mecánico, comparaban los principales chefs de su tiempo con Rafael, Miguel Angel y Rubens. ${ }^{17}$ En este sentido William Kitchiner, en The Cook's Oracle, estableció un comité del gusto, basado en el jurado de degustadores de Grimod de la Reynière, que se aplicaba a juzgar recetas filosóficamente mostrando desinterés hacia cuestiones de pura mecánica fisiológica como los dientes o el estómago.

En cuanto al segundo servicio del que habla Gigante, la cultura de la gastronomía, la coffeehouse, que había conformado la vida intelectual de la Europa de la Ilustración y el restaurante, desarrollado después de la Revolución Francesa, emergen como escenarios públicos preferentes del ejercicio de la degustación gastronómica. La diferencia fundamental entre el café de la ilustración y el restaurante, es que el primero no tenía la comida como elemento central. En la coffeehouse la política y el arte eran temas fundamentales de conversación, pero todo esto cambió una vez que el restaurante, espoleado por los talentosos chefs franceses, estimuló las artes de la gastronomía. Con la más abstracta apreciación mental de la belleza reducida a los placeres materiales de la mesa, un número mayor de consumidores se encontraron buscando distinción cultural a través de sus paladares, incrementándose así la clientela del restaurante. ${ }^{18}$ Quizás el establecimiento inglés más próximo al restaurante francés

17 Haciéndose eco de este triunvirato, de hecho, el historiador gastronómico Abraham Hayward clasificaba el arte culinario en dos escuelas: la clásica, encabezada por Antonin Beauvilliers y la romántica, liderada por Antonin Carême, afirmando «que Beauvillers se distinguía por su juicio y Carême por la invención». Hayward, Abraham, The Art of Dining; or, Gastronomy and Gastronomers, John Murray, Abermarle Street (London, 1852), p. 29

18 El restaurante también se diferenciaba del inn inglés o de la francesa table d'hôte, que habían servido como lugares públicos de comida desde la Edad Media. Aunque el inn era una institución más alimentaria que la coffeehouse, no ofrecía un menú variado para adecuarse al gusto individual. En el inn, al igual que en la table d'hôte, la comida se servía generalmente en una mesa ordinaria y el menú era poco más que una lista de los platos que se servían, con sus pecios correspondientes. Estas comidas no eran discriminatorias, ya que el comensal no se encontraba allí por causa de la comida. Los que allí se alojaban, trataban la comida como una necesidad y no como un objeto del arte.Véase Crewe, Quentin, Great Chefs of France, Littlehampton Books Service (Worthing, 1978). Véase también la 
fuese la tavern inglesa de finales del siglo XVIII, cuyos cocineros se enorgullecían de sus platos y que, al igual que los más refinados chefs de la corte, a menudo publicaban sus recetas en obras culinarias como fue el caso de John Farley. ${ }^{19}$

Recientemente, algunos autores han enfatizado la profunda relación existente entre la oferta de estos primeros restaurantes, el mundo filosófico de la Ilustración y el ascenso de las ideas como las del individualismo y la privacidad en el contexto del despliegue de una nueva sociedad liberal y burguesa. Rebecca Spang, en este sentido, subraya cómo el restaurante, con sus mesas separadas que ofrecían un espacio individualizado para comer, proporcionaban al cliente una opción para satisfacer sus preferencias personales dentro de los estándares del gusto que ofrecía el cocinero; en consecuencia estos lugares constituían la «forma física» de unos patrones abstractos de sensibilidad y gusto, tanto intelectuales como de placer corporal, proporcionando el escenario adecuado para expresar «la tensión entre la opción privada y los estándares universales que habían marcado la estética del siglo XVIII». Kenneth Bendiner, a su vez, también apoya estas tesis de Rebecca Spang con respecto a una visión del restaurante como una institución en la que los comensales hacían converger los ámbitos público y privado, en el momento en que,

obra Burnett, John, England Eats out. 1830 - Present, pp. 66-102. Es fundamental el trabajo anónimo contemporáneo London at Table, or How, When and Where to Dine and Order a Dinner, and Where to Avoid Dining, Chapman and Hall (London, 1851), que en su página 40 hace referencia a las reuniones gastronómicas intelectuales: «El objeto de la solicitud doméstica es esforzarse en combinar confort y sistema con economía en el trato social y trazar una línea entre un banquete (dinner party) para cuatro, seis u ocho personas (y que, con una proporción equitativa de damas puede llegar hasta doce) y otros banquetes para un número elevado de comensales». Casi a renglón seguido, la anónima guía gastronómica elogia las obras de Ude, Soyer y Meg Dodds y, en las cinco páginas siguientes explica pormenorizadamente cómo se debe servir un banquete à la Russe, que definía como una práctica «absolutamente esencial». Anónimo, London at Table, or How, When and Where to Dine and Order a Dinner, and Where to Avoid Dining, p. 41.

19 Etimológicamente, tavern procede del latín taberna, un lugar público o barracón construido con tableas. Sin embargo, el término restaurant, como hemos visto, tiene su origen en una comida, una sopa o caldo que se extraía de carnes selectas, verduras frescas y otros ingredientes saludables. La mayoría de los gastrónomos del siglo XIX conocían la historia de Roze de Chantoiseau, propietario del Champ d'Oiseaux, que en 1756 ofrecía estos caldos restauradores bajo un lema (motto) en latín, que rezaba: «Venite ad me, omnes qui estomaco laboratis, et ego vos restaurabo». Estos delicados caldos constituyeron el primer alimento que se ofrecía en los restaurantes y convergían con el culto a la sensibilidad y delicadeza del siglo XVII, tanto para el cuerpo como para la mente. 
mientras se aíslan en pequeños grupos, simultáneamente exhiben su privacidad públicamente. ${ }^{20}$

El surgimiento del restaurante fue una consecuencia directa de la Revolución Francesa puesto que, una vez que los acontecimientos políticos de la década de 1790 liberaron de su patronazgo aristocrático a los chefs más renombrados, éstos pasaron a formar parte del mercado abierto de París, estableciéndose como restauranteurs en hoteles abandonados o en las arcadas del Palais Royale. Con los aristócratas franceses huidos a otras ciudades de Europa, los chefs se encontraron atendiendo a una nueva clientela burguesa, los nuevos ricos. Los años gloriosos del restaurante en París tuvieron su máximo esplendor entre 1815 y 1830, cuando los menús, al igual que la novela, se expandieron hasta alcanzar cotas de gran excelencia. Los extranjeros que viajaban a Francia se sorprendían ante la abrumadora variedad culinaria que se ofrecía al otro lado del canal y, aunque la guerra entre Gran Bretaña y Francia había hecho difícil viajar entre los dos países a partir de 1793, la gastronomía despegó repentinamente en Inglaterra tras la derrota de Napoleón en Waterloo, en 1815. ${ }^{21}$

Como se ha visto anteriormente, la realeza y aristocracia británicas contrataron a los grandes chefs franceses. Tal es el caso del príncipe Regente George de Hanover, posteriormente George IV, quien contrató a Carême; máximo representante de la escuela gastronómica romántica. Carême preparó banquetes de cien platos para el príncipe y sus invitados en Brighton, transformando la estancia de verano real en un referente internacional e introduciendo a la nación británica en la cocina francesa de vanguardia. La King's Kitchen del Brighton Pavillion se con-

${ }^{20}$ Sobre las tesis de Rebecca Spang, véase: Gigante, Denise, Gusto. Essential Writings in Nineteenth-Century Gastronomy, Routledge xxviii. A su vez, en Food and Painting, Kenneth Bendiner subraya: «Comen con otros y, a la vez, están separados. Si verdaderamente deseasen privacidad, podrían comprar la comida y consumirla en otro lugar; sin embargo, se quedan en el restaurante y se exhiben. Es una negociación de socialización en una sociedad de masas. Spang, sin duda, tiene razón al percatarse del carácter conversacional y de intimidad de la experiencia del restaurante como un hecho fundamentalmente diferente de los grupos de discusión abierta y el ambiente completamente público de la coffee house, tal y como había existido en los siglos diecisiete y dieciocho. Esos lugares eran simposios políticos, científicos e intelectuales desplegados en Inglaterra y en Francia». Bendiner, Kenneth, Food in Painting: from the Renaissence to the Present, Reaction Books Ltd. (London, 2004), p. 146.

${ }^{21}$ Es significativo que John Burnett, en su obra, England Eats Out. 1830 - Present, establezca 1830 como año a partir del cual los establecimientos públicos de comidas comenzaron a tener cierta relevancia. 
virtió en la cocina europea más avanzada tecnológicamente. De esta manera, Francia desencadenó una revolución culinaria en Gran Bretaña, donde surgieron nuevas instituciones como clubs y restaurantes, con la función de satisfacer el estilo de vida y gustos de las clases medias emergemtes. El propio George IV se hizo socio de la Sublime Society of Beefsteakes, institución que, al igual que otros clubs ingleses, hacía alarde de emplear a un chef francés. ${ }^{22}$

Una vez que el alto estilo gastronómico parisino se impuso en Londres, las clases medias británicas abandonaron el pub. El pub se parecía a la tavern en que su función primaria no era el albergue sino la comida, aunque servía cerveza en lugar de vino. Con más gente intentando adquirir distinción a través de la comida, el lenguaje culinario se hizo francés, y mientras que muy a principios del siglo XIX sólo algunas casas y clubs privados podían permitirse el lujo de servir haute cuisine francesa, hacia mediados de siglo estaba admitido que adquirir gusto era asumir hábitos culinarios franceses. Por otra parte, los propios restauranteurs franceses se consideraban misioneros de la civilización, diseminando sus ideales de gusto cultural y apetito adquirido más allá de las fronteras de Francia, y como todo arte tiene sus exégetas, estos profesionales recibían asistencia en esta tarea por parte de los escritores gastronómicos. En sus viajes a París entre los años 1802 y 1805, John Pinkerton destacaba que el Almanach des Gourmands de Grimod de la Reynière abarcaba una rama de lujo cultivada por los nuevos ricos. ${ }^{23}$

La importancia de la gastronomía como arma diplomática, por otra parte, era bien conocida por Napoleón, que a pesar de no ser un gastrónomo enviaba a los diplomáticos y dignatarios a comer con su archicanci-

${ }^{22}$ Sobre este prestigioso club londinense, fundado por John Rich en 1735, que tenía entre sus miembros a personajes tan destacados como William Hogarth, y en cuyas filas ingresó el Príncipe de Gales el 7 de mayo de 1785, es fundamental la obra de Walter Arnold. Arnold, Walter, The Life and Death of the Sublime Society of Beef Steaks, Bradbury Evans, \& CO (London, 1871).

23 «La famosa obra titulada Almanach des Gourmands de Grimod de la Reynière puede servir considerablemente como libro de texto que trata de los lujos de París. Pero cubre tantos aspectos que varios extractos o, más bien, observaciones pueden ser suficientes para su consideración. Esta obra, en efecto, sólo abarca una rama del lujo; pero se trata de un aspecto cultivado en particular por los nuevos ricos, cuyas bodegas y despensas están mucho mejor surtidas que sus bibliotecas. Este gusto ha llegado a ser tan general que los libreros se han convertido en traiteurs y encuentran al alimento corporal más beneficioso que el mental». Pinkerton, John, Recollections of Paris, in the Years 1802-3-4-5., Longman Hurst Rees \& Orme (London, 1806), pp. 195, 196. 
ller Cambacérès, que había contratado a Carême como su chef. Además de Cambacérès, Napoleón se beneficiaba políticamente del gusto esquisito de su Ministro de Asuntos Exteriores, Charles-Maurice de TalleyrandPérigord, a quien Carême consideraba el más refinado de sus empleadores. ${ }^{24}$ Las relaciones internacionales contribuían, pues, a la difusión gastronómica.

Tras recorrer la dimensión cultural de la gastronomía, Gigante aborda su componente literario destacando, como se ha visto en este trabajo, el Almanach des Gourmands de Grimod de la Reynière como texto fundador de esta peculiar literatura gastronómica. En Inglaterra, como se ha visto, el primer texto específicamente gastronómico fue el anónimo The School of Good Living, publicado en 1814, y sólo tres años más tarde, en 1817, veía la luz The Cook's Oracle del doctor William Kitchiner, en donde se establecía el Committee of Taste con funciones semejantes a las que tenía el precedente Jury de Gourmands dégustateurs en la obra de Grimod. La obra de Kitchiner, ciertamente, fue muy aclamada en Londres llegando a competir en popularidad con las obras de Walter Scott y Lord Byron. Pero en todo caso, al igual que otros escritores románticos, los gastrónomos en general consideraban su deber instruir a la nación en cuestiones de gusto, y tanto Wordsworth como Coleridge hicieron referencia explícita al gusto gastronómico como principio esencial de sus escritos.

Por otra parte, desde la perspectiva culinaria tradicional británica, el proyecto de identificar los principios filosóficos de la comida estaba enmarcado en la preferencia francesa por la sensualidad, el lujo y, más en particular, el despilfarro. Como ya se ha apuntado en este trabajo, era una constante dentro de la tradición culinaria británica del siglo XVIII la referencia al despilfarro, del que los chefs franceses hacían ostentación; siendo capaces de sacrificar cincuenta jamones para extraer el cullis, la quintaesencia de las salsas francesas. Esta operación de condensación de

${ }^{24}$ Denise Gigante, al final de su disertación sobre la cultura gastronómica, condensa la importancia sociopolítica de la gastronomía en los siguientes términos: «La gastronomía, como expansión cultural-material de la filosofía del gusto, incorpora este aspecto de la comensalidad: revela la naturaleza social del sensus communis, o comunidad estética unida mediante ideas compartidas del placer. A los teóricos del gusto de la Ilustración les concernía la deliberación racional respecto a cuestiones de la belleza, aunque se daban por satisfechos con dejar al individuo a su libre albedrío ante sus preferencias gustativas privadas. Los gastrónomos, por el contrario, aplicaban el mismo imperativo para el consenso social hacia la comida como un medio artístico». Gigante, Denise, Gusto. Essential Writings in Nineteenth-Century Gastronomy, Routledge, xxxii. 
la esencia, de todos modos, era para las cocineras inglesas como Hannah Glasse más un desperdicio que una habilidad. En esta misma dirección, la afición francesa a los fricasés y a otros ornamentos culinarios, tales como las salsas, que constituían el fundamento de la haute cuisine francesa, les parecía a los ingleses una manera de enmascarar la auténtica naturaleza de los alimentos.

A lo largo del siglo XVIII, los ingleses se habían enorgullecido de su sentido común, de ser un pueblo que comía ternera y hablaba claro, sin paciencia para la ostentación foránea, especialmente la de su tradicional enemigo, Francia. Sin embargo, el género literario gastronómico, quizás reconociendo de antemano este potencial para el rechazo crítico, desarrolló su propio estilo satírico, a la vez que cultivaba lo específico de su genio racional incluso allí donde, como en el caso de la gastronomía, se tendía a reconocer la iniciativa francesa.

En su exuberancia, el gourmand de principios del siglo XVIII puede considerarse como un hermano gemelo del flâneur, es decir, en términos ingleses, del dandy. El gourmand trataba la comida como un tema de peso para el debate filosófico y el dandy fue el primero en hacer de la indumentaria y de la moda la base de la filosofía que era consistente con la vida moderna materialista y apegada al consumo. Como explican los historiadores sociales Leonore Davidoff y Catherine Hall, el dandy no es más que la masculinidad domesticada dedicada a los negocios. ${ }^{25}$ Los gastrónomos se parecían a los dandies como filósofos contractuales, en tanto en cuanto vivían para comer y no al contrario, comiendo para vivir adoptando el modo ascético socrático. Mientras la moralidad burguesa exigía una acumulación de energías para poder dedicarlas al trabajo, los gourmands invirtieron esta fórmula tradicional para afirmar, según el espíritu de los dandies, que el trabajo es sólo un medio para alcanzar el placer. ${ }^{26}$

25 Davidoff, Leonore, The Best Circles: Society, Etiquette and the Season, Croom Helm (Kent, 1973). Véase también Hall, Catherine, Family Fortunes: Men and Women of the English Middle Class 1780-1850, Taylor \& Francis Ltd. (London, 2002). Para un estudio del dandismo en la primera mitad del siglo XIX, véase Cole, Sarah Rose, «The Aristocrat in the Mirror: Male Vanity and bourgeois Desire in William Makepeace Thackeray's Vanity Fair», Columbia University, LXI (2006), pp. 137-170.

${ }^{26}$ Stephen Mennel establece la misma comparación entre gastrónomos y dandies, especificando que, mientras que la figura del gastrónomo surgió en Francia, La figura del dandy, surgió al otro lado del Canal: «¿Por qué, entonces, apareció el gastrónomo como una figura claramente definida en la Francia posrevolucionaria? Posiblemente resulte reveladora una comparación con el dandismo. Un dandy, (el que se concentra por encima de 
$\mathrm{Al}$ contrario que las formas dieciochescas de comer, codificadas como femeninas al estilo, por ejemplo, de la conocida cocinera y escritora Hannah Glasse, la estética gastronómica del siglo XIX era masculina al igual que el dandy culinario de gusto modernizado; no es extraño, por tanto, que los escritores gastronómicos trabajasen de distintas maneras en contra de la estética feminizada de la novela, cimentada en ideales de domesticidad burguesa. Por otra parte, los textos gastronómicos se situaron en una posición apartada de la corriente general que había impulsado la forma comercial de la novela, y mostraron cierta afinidad con los poetas contemporáneos, como defensores de las artes y de lo artístico, y cada vez más definidos como un puro esteticismo en el mundo consumista del siglo XIX.

Sea como fuere, la cuestión gastronómica fue abordada por los escritores románticos desde un punto de vista radicalmente opuesto al de los clásicos, que favorecían la extravagancia, como en el caso de los grandes banquetes romanos, con platos únicos cocinados, por ejemplo, con cientos de sesos de faisán. Sin embargo, a pesar de haber abandonado a los clásicos como modelos de gusto, los románticos recurrieron a ellos en busca de autoridad textual. Esta tendencia se manifiesta de manera evidente en las historias eruditas del arte de la cocina, que suelen remontarse al primer gran cocinero griego Cadmus. Dick Humelbergius Secundus, seudónimo referente a un supuesto anotador romano del siglo XVI de la obra de Apicius, dedica al menos la mitad de sus Apician Morsels (1829) a la cocina y a las prácticas culinarias de los comensales de esta época.

En contra de una sensibilidad tradicionalmente asimilada a lo británico, es también característico de los escritores gastronómicos románticos consentir, e incluso alabar la crueldad de los cocineros hacia los animales, si esto es necesario para preparar un buen plato. Charles Lamb, encarnado en su personaje Elia, defiende la flagelación de los cerdos en vida para hacer que su carne sea más tierna. Abraham Hayward en su Art of Dining defiende estas crueles prácticas afirmando que el gastrónomo debía ser tan insensible ante el sufrimiento como el conquistador. Tanto Hayward como Grimod son partidarios de la tortura a la que se somete a los gansos

todo a vestir de forma elegante y a la moda: un galán, un lechuguino, un exquisito (Oxford English Dictionary), es una figura más oriunda de Inglaterra que lo que podría ser un gastrónomo y la palabra se puso de moda hacia 1813-19 con las oleadas de la moda del periodo de la Regencia. El dandy es con respecto a la vestimenta lo que el gastrónomo es en con relación a la comida». Mennell, Stephen, All Manners of Food. Eating and Taste in England and France from the Middle Ages to the Present, p. 273. 
apara agrandar su hígado y así conseguir el delicado paté de Estrasburgo. La estética romántica se configuraba así como un espacio de rebeldía y de desorden frente a la batalla abierta a favor de la racionalización de las costumbres y en contra de los bloody sports y la crueldad hacia los animales, espoleada por sectores religiosos, patronales y políticos, y especialmente activa entre 1750 y $1850 . .^{27}$

La puntualidad es otra de las características postuladas por los gastrónomos románticos. Los invitados pueden esperar por el cocinero, pero no al contrario. La prioridad es la comida y el cocinero es el artífice de esta fundamental preparación. Este precepto se oponía a los códigos tradicionales, en cuya escala de prioridades el cocinero era un sirviente anónimo del invitado. Por otra parte, el apetito es fundamental, dentro de la jerarquía de valores del gastrónomo romántico. El cambio que se produjo a mediados de siglo, pasándose del servicio à la Française, mediante el que se presentaban todos los platos disponiéndolos simultáneamente sobre la mesa y divididos en tres series, al servicio à la Russe, consistente en una sucesión de los platos servidos como objetos individuales de gusto, acentúa este respeto por el apetito del epicúreo y su capacidad de hacer justicia a una buena comida. Todas estas prácticas, conjuntamente, destacaron el arte culinario del chef, quien ya no era un personaje anónimo, sino una figura con prestigio social y cultural.

Los gastrónomos románticos también desafiaron los códigos existentes con respecto a la mujer como elemento estético. Tradicionalmente, el comportamiento elegante había sido que un caballero diese prioridad a

27 «Un verdadero gastrónomo es tan insensible ante el sufrimiento como un conquistador. Ude argumenta de esta manera respecto al desollado de las anguilas: "coger una o dos anguilas, arrojarlas al fuego, y cuando se retuercen hacia todos los lados, sujetarlas con una toalla en la mano y desollarlas desde la cabeza hasta la cola. Éste método es el mejor porque, de esta manera, se les extrae el aceite, que es indigesto y de sabor desagradable"». Hayward, Abraham, The Art of Dining, or Gastronomy and Gastronomers, pp. 112-114. En las mismas páginas se encuentran referencias a la flagelación de los cerdos y a la tortura de los gansos. La tortura a los animales, antes de la cruzada de los movimientos religiosos reformadores e inconformistas, era una práctica generalizada en Inglaterra, e incluso una fuente legítima de enriquecimiento. Véase Malcolmson, Robert, Popular Recreations in English Society, Cambridge University Press (Cambridge, 1993). Paradójicamente, la misma sociedad cuyos gastrónomos ejercían estas crueles prácticas con los animales, fundó en 1824 la «Society for the Prevention of Cruelty to Animals», lo que es un indicativo más de la ambivalencia moral característica de la sociedad victoriana. Véase Mennell, Stephen, All Manners of Food. Eating and Taste in England and France from the Middle Ages to the Present, pp. 306-307. 
una dama que se sentase a su lado, antes que ocuparse de la comida. En la estética romántica, toda la atención debe concentrarse en lo que hay en la mesa y no en lo que la rodea, y las mujeres no deben esperar atención hasta que el postre esté servido. Esta falta de galantería en la mesa se oponía otra vez al universo mercantilizado de la novela, uno de cuyos argumentos era el del casamiento, en el que los dinner parties y reuniones sociales eran un medio para llegar al final romántico.

Finalmente, y para concluir con el esquema de Denise Gigante - aunque no exactamente con su argumentación - las obras gastronómicas no debían tender a ser misceláneas, sino antológicas. El típico gastrónomo romántico británico se consideraba un recopilador de pequeños fragmentos selectos de otras obras, un coleccionista de trozos y remiendos ordenados, de la misma manera que William Hazlitt definía los libros nuevos en su ensayo On Reading Old Books.

Cuando el entretenimiento es completamente nuevo, me siento ante él como lo haría ante un plato nuevo y estoy dudoso sobre qué pensar de su composición. En el segundo apetito hay una carencia de confianza y de seguridad. Los libros nuevos son también como los platos preparados, en el sentido en que son generalmente poco más que troceados y rifaccimentos de lo que en otros momentos hubiera sido servido en una pieza y en un estado más natural. ${ }^{28}$

Las referencias de fondo de toda esta literatura gastronómica, sin duda, a la vez que los verdaderos fundadores de la tradición gastronómica romántica son, de todos modos, los franceses Alexandre Balthasar Laurent Grimod de la Reynière (1758-1838) y Jean-Anthelme Brillat-Savarin (1755-1826).

Grimod de la Reynière fue un genio que se hallaba detrás de la tradición gastronómica romántica. Aunque haya sido eclipsado por Jean-Anthelme Brillat Savarin, cuya Physiology of Taste (1826) recapitula en un solo volumen muchas de las ideas más refinadas de Grimod sobre la comida y la buena vida, la obra de este último tuvo una enorme influencia en la Europa del siglo XIX. Si sus trabajos son importantes - sobre todo el Almanach des Gourmands (1803-1812) y el Manuel des Amphitryons (1808) - quizás una de las ideas más peculiares de la personalidad de

${ }^{28}$ Hazlitt, William, «On Reading Old Books», en The Plain Speaker: Opinions on Books, Men, and Things, Vol. II, Henry Colburn (London, 1826), p. 65. 
Grimod fuese la fundación de su Jury Dègustateur, su grupo de gourmets selectos que se reunía semanalmente en el Hotel de la Reynière para probar y juzgar los más refinados productos culinarios de París. Cada una de sus 465 sesiones duraba cinco horas y sus veredictos oficiales se publicaban en el Almanach des gourmands.

Physiology du goût de Brillat-Savarin, al igual que Almanach des gourmands, es un pot pourry de aforismos gastronómicos, diálogos entre el autor y sus correligionarios en gastronomía, unas treinta meditaciones y una mezcla de aventuras, inventos, recetas y anécdotas. Brillat-Savarin reconoció su deuda con las obras de Grimod de la Reynière, aunque existe una notable diferencia entre estos dos padres fundadores de la gastronomía francesa. Mientras que Grimod era un aristócrata de la Francia del ancien-régime, con un ilustre gourmet y ávido anfitrión como padre, Brillat-Savarin fue un miembro de la burguesía que se hizo a sí mismo. Como tal, se convirtió en el portavoz del futuro gastronómico de la Francia posrevolucionaria. Entre sus aforismos, el más conocido es, sin duda «Dime lo que comes y te diré quién eres», aunque no era ni mucho menos el único. ${ }^{29}$

\section{Los discípulos británicos de Grimod de la Reynière y Brillat-Savarin. Una obra pionera: The Cook's Oracle (1817)}

Como se ha visto, los padres indiscutibles del género gastronómico eran en conclusión, Grimod de la Reyniére y Brillat-Savarin. Al tratarse de gastrónomos franceses, sin embargo, han de tener aquí un espacio limitado; nuestro interés ha de centrarse, por el contrario, en sus discípu-

29 Tómense como ejemplo los siguientes: «El hombre dispéptico y el borracho no son incapaces de comer ni de beber»; «Invitar a alguien implica que somos responsables de su felicidad mientras esté bajo nuestro techo»; «Esperar demasiado tiempo por un invitado que tarda es una falta de consideración hacia los invitados que están presentes»; «El descubrimiento de un nuevo plato es más beneficioso para la humanidad que el descubrimiento de una nueva estrella». Aunque a lo largo de las páginas anteriores se ha disertado sobre las características del género literario gastronómico, utilizando indistintamente gastrónomos franceses e ingleses, el objeto de este trabajo es estudiar a los gastrónomos británicos y no a otros. Para una sucinta biografía de Grimod de la Reynière véase Gigante, Denise, Gusto. Essential Writings in Nineteenth-Century Gastronomy, pp. 1-4 y 141-144. Véase también Mennell, Stephen, All Manners of Food. Eating and Taste in England and France from the Middle Ages to the Present, pp. 267-269. 
los británicos más directos comenzando con un original personaje, el doctor William Kitchiner. Su trabajo, sin embargo, es difícil de clasificar, ya que puede ser considerado una simple obra culinaria al tratarse de un recetario, compuesto de excéntricas composiciones, a la vez que también puede contemplarse como una obra gastronómica al incluir reflexiones más generales sobre la comida, la masticación, la digestión y los alimentos.

Kitchiner adoptó la moda francesa de tratar la comida como un arte refinado y a la cocina como un medio para la expresión y para la invención individual. Su obra, Apicius Redivivus; or the Cook's Oracle (1817) llevaba como prefacio un ensayo en forma de tratado gastronómico. Afirmaba que cada una de sus recetas había sido sometida a un comité del gusto o jurado gastronómico basado en el modelo de Grimod de la Reynière. En realidad, su trabajo no fue el primer ensayo gastronómico que apareció en inglés pero sí el que tuvo más influencia al trasladar eficazmente la gastronomía francesa a la cultura inglesa, introduciendo al público lector británico en el concepto del epicúreo racional, y aplicando a la cocina el conocimiento fisiológico de la época al estilo de Brillat-Savarin.

Muy lejos del típico libro de cocina, The Cook's Oracle fue considerado por la crítica en 1842 como un cúmulo de excentricidades o como una extraña mezcla de recetas, observaciones y máximas extraídas de todas las fuentes: antiguas, modernas, extranjeras y del país. Todavía en la actualidad los gastrónomos siguen describiéndolo como el libro de cocina menos práctico jamás escrito. Su texto está salpicado de alusiones a Milton, Pope, Southey y Byron y denuncia a todos los libros de cocina escritos anteriormente como menos útiles que leer Robinson Crusoe para llegar navegando desde Inglaterra hasta India. Pese a su tono de recetario The Cook's Oracle inicia, por tanto, la tradición gastronómica inglesa como un género filosófico literario para escribir sobre la comida.

Richard Chenevix, en 1821, subrayaba que las recetas fueron escritas al lado del fogón, con la manivela del asador en una mano y la pluma en la otra; de hecho Kitchiner asegura que jamás recomendaría una sola de sus recetas sin haberla experimentado previamente en su cocina. Todas sus recetas, además, recibieron la bendición de cocineros de calidad contrastada, y probadas con el aplauso unánime del Comité del gusto. Al igual que los filósofos del gusto del siglo XVIII, en consecuencia, Kitchiner fue un empirista comprometido con alcanzar el juicio correcto a través de la experimentación desinteresada. El propio título del libro alude al de Baltasar Gracián, El oráculo: Un manual del arte de la discreción; una referencia 
que los filósofos estéticos a partir de Joseph Addison, en 1711, tomaron como punto de referencia para redefinir el concepto del gusto.

Al contrario que la cocina francesa, basada en el modelo cortesano, el modo gastronómico de Kitchiner insiste en la economía en el lenguaje, a la vez de en el arte culinario. Su intención era eliminar un cúmulo de términos inapropiados y sin significado, muchos de ellos vocablos corrompidos procedentes del francés, pero en uso cotidiano por los escritores culinarios de la época. Aunque Kitchiner afirma haber leído más de 200 libros de cocina antes de escribir el suyo, no menciona ninguno escrito por los cocineros franceses que trabajaban en Inglaterra durante aquellos años; y en concreto, los de Louis Eustache Ude y Charles Elmé Francatelli. Ambos autores y cocineros franceses criticaron a Kitchiner por sus «términos manidos» y sus «improvisaciones económicas»; y de hecho su recetario ha sido considerado sistemáticamente como plenamente perteneciente a la tradición inglesa, aunque la obra de Kitchiner, en cuanto a su componente estrictamente gastronómico, sigue desde luego la tradición francesa. De hecho, la única cocinera a la que hace referencia es a Elizabeth Raffald y a sus dos recetas: Mrs. «Raffald's Browning» y «Mrs. Raffald's Lemon Pickle».

La obra comienza con un extenso prólogo, seguido de una sección de consejos a los cocineros; en total unas cuarentas páginas. A estas dos secciones les sigue un extenso inventario de recetas, en muchas de las cuales se incluyen observaciones que se inclinan más hacia el lado gastronómico.

Comienza Kitchiner explicando que su obra no consiste en una colección de jirones, parches, recortes y pegados sin meollo, sino en un registro de hechos prácticos acumulados por la perseverancia y que no han de evaporarse fácilmente ante la censura de la Cook's Company, por intentar preservar los profundos misterios del oculto arte de la cocina. Insiste el gastrónomo en que ha escrito su obra con el espetón en una mano y la pluma en la otra, y en que ha probado todas las recetas antes de transcribirlas al libro para finalizar disculpándose por haber incorporado un menor número de recetas que otros autores anteriores. Sin embargo, concluye, todo ha sido para el beneficio y el placer del dueño de todo ser humano, el estómago. ${ }^{30}$

${ }^{30}$ Kitchiner, William, Apicius Redivivus; or, The Cook's Oracle, Printed for Samuel Bagster (London, 1817) No. a3, a4. Tras esta puntualización, Kitchiner añade una nota de pie de página en la que define el estómago: «El estómago es el gran órgano del sistema humano de cuyo estado dependen todos los poderes y sentimientos del individuo». Kitchiner, William, Apicius Redivivus; or, The Cook's Oracle, No. a3 
Es tan peculiar la obra de Kitchiner que, habiendo elaborado un recetario inspirado en la más pura tradición inglesa, sus primeros capítulos, a saber el prefacio y los consejos a los cocineros, contienen máximas, preceptos y reflexiones culinarias que podrían ser firmadas por Grimod o Brillat-Savarin. Aparecen, incluso, alabanzas a la cocina francesa. ${ }^{31}$

Entre los aforismos y prescripciones culinarias que salpican la sección gastronómica de The Cook's Oracle, destacan las que definen de forma más precisa la filosofía gastronómica de Kitchiner; a saber, las cuatro virtudes cardinales de la cocina: el carácter empírico del recetario, el componente filosófico de la cocina, el hedonismo que se manifiesta en proporcionar placer al paladar, y la preocupación por la salud, puesto que este placer excelso no debía alcanzarse a expensas de un daño a los dientes o al estómago o «víscera principal».

Las virtudes cardinales de la cocina, la limpieza, la frugalidad, la nutrición y la palatabilidad presiden cada preparación. Porque no he pretendido incluir ni una sola composición si haber obtenido previamente el «imprimatur» del más ilustrado e infatigable Comité del gusto, cuya cooperación cordial y perseverante nunca podré elogiar suficientemente. Y aquí hago constar con gran placer el implacable celo del que sus miembros hicieron gala durante el arduo proceso de probar filosóficamente y de forma desinteresada, las correspondientes recetas a expensas del uso y desgaste de sus dientes y de sus estómagos, dando la impresión de que su trabajo les proporcionaba placer. Esta encomiable perseverancia me ha capacitado para dar al más inexperto amateur esta inequívoca guía sobre cómo extraer tanto placer como sea posible del paladar, causando los mínimos problemas posibles a la víscera principal. ${ }^{32}$

Es también fundamental la manera en la que Kitchiner define al hombre epicúreo, al gastrónomo, teniendo sumo cuidado en diferenciarlo del glotón; que no necesita los sesos de loros o de los pavos reales, ni las lenguas de los zorzales o de los ruiseñores para proporcionar placer al paladar. ${ }^{33}$ Tras ci-

31 «Nuestros vecinos de Francia son con tanta justicia famosos por su destreza en los asuntos de la cocina que el adagio reza: "Tantos franceses, tantos cocineros". Rodeados como están por tanta profusión de los más deliciosos vinos y los más seductores licores, que ofrecen toda tentación de proporcionar una embriaguez deliciosa, un francés borracho es "rara avis"». Kitchiner, Apicius Redivivus; or, The Cook's Oracle, B4. Véase también Gigante, Denise, Gusto. Essential Writings in Nineteenth-Century Gastronomy, p. 61.

${ }_{32}$ Kitchiner, William, Apicius Redivivus; or, The Cook's Oracle, A4.

33 Ibidem, A4. 
tar a Milton, a Shakespeare y a Descartes, vuelve a ocuparse del estómago, al que considera el origen de todo el sistema corporal. ${ }^{34}$ La fisiología digestiva se vuelve aquí, en consecuencia, resultado de la cultura y pretexto para la meditación filosófica. No desdeña el autor, sin embargo, las bases físicas de la asimilación digestiva, y de hecho otra peculiaridad de The Cook's Oracle la constituye la referencia a la masticación; para la que remite al lector al Almanach des Gourmands de Grimod, y advierte de que aquella persona que no trabaje con la mandíbula está invitando a la indigestión. ${ }^{35}$

The Art of Invigorating and Prolonging Life by Food, Clothes, Air, Exercise, Wine, Sleep, \&c. and Peptic Precepts, es la segunda obra gastronómica del doctor Kitchiner, de la que apareció una crítica en la Edinburgh Review en $1821 .{ }^{36}$ Peptic Precepts se concentra íntegramente

34 «El estómago es el resorte principal de nuestro sistema. Si no tiene la suficiente cuerda para calentar el corazón y mantener la circulación, toda la cuestión de la vida funcionará proporcionalmente de forma ineficaz. No podremos tampoco: pensar con precisión, caminar con vigor, sentarnos con comodidad ni dormir placenteramente». Gigante, Denise, Gusto. Essential Writings in Nineteenth-Century Gastronomy, p. 62. Denise Gigante utiliza la edición de The Cook's Oracle de 1831 y esta definición del estómago no había aparecido en la primera edición de 1817.

35 «Cuanto más tierna sea la carne, más cantidad puede que comamos. El número de masticaciones que debemos darle es de entre treinta y cuarenta, con el fin de prepararla para su viaje de descenso a través del "canal rojo". Trabaja con la mandíbula, o invita a la indigestión si abandonas la masticación. No puedo dar ninguna regla para esto, pues depende en gran medida de la fortaleza o debilidad del sujeto en cuestión, especialmente de sus dientes y de sus glándulas maxilares: cada persona debería asegurarse del estado de esta útiles herramientas de trabajo, y utilizarlas con proporcionada diligencia constituye un ejercicio indispensable que todo epicúreo racional que sienta verdadera estima por el bienestar de su estómago deberá practicar». Almanach des Gourmands, vol. iii. Page 249, \&c. «La masticación es el origen de toda Buena digestión. Con ella, se puede introducir en el estómago cualquier cosa con impunidad. Sin ella, la digestión ha de ser siempre difícil y frecuentemente imposible. Y recuérdese: lo que nos nutre no es sólo lo que comemos, sino lo que digerimos bien. El gourmand sagaz tiene en todo momento presente su lema: masticar, denticar, mascar, moler y tragar. Los cuatro primeros actos deben realizarse bien, antes de atreverse a intentar el quinto». Kitchiner, William, Apicius Redivivus; or, The Cook's Oracle, (preface), sin página.

36 «Sin embargo, no debemos olvidarnos de hacer plena justicia al Dr. Kitchiner, quien no ha hecho su trabajo en mitades. La indigestión es una cuestión estrechamente relacionada con el buen comer; sin embargo, en Francia, no parece que sea la causa de tal lacra y tormento como es en este país. "La digestión — dicen los franceses - es el asunto del estómago y la indigestión es el asunto del médico. Sin embargo, si alguien por alguna incauta indulgencia en las buenas cosas que aparecen en The Cook's Oracle la padeciese, puede recurrir a Peptic Precepts donde se advierte de los síntomas más prevalentes de la indigestión y se prescriben los antídotos más efectivos"». The Edinburgh Review, MARCH, 1821, N. ${ }^{\circ}$ LXIX, pp. 61, 62. 
en la cuestión de la indigestión, contra la cual el galeno proporciona consejos y remedios. Kitchiner desconfía, por ejemplo, de las Aperient Pills, o laxantes, que no son más que drastic purgatives que acaban irritando el estómago. Aparentemente se trata, por tanto, de una obra concentrada en desórdenes puramente fisiológicos.

La indigestión, en este sentido, supera al más experimentado gastrónomo, cuando los nervios se hallan en un estado de buen humor. El hambre y las viandas sabrosas a veces seducen la lengua de un «Grand Gourmand», afirma Kitchiner, para traicionar el interés de su estómago, y bien a pesar de su cerebro. En ese caso, la abstinencia se prescribe como la mejor cura para la indigestión; sin perjuicio de que algunas veces sean necesarias preparaciones específicas o remedios caseros, basados siempre en el conocimiento que Kitchiner poseía de todo el proceso digestivo 37. Peptic Precepts está dotado, en general, del mismo tono que la parte gastronómica de The Cook's Oracle y repite, aunque con ingeniosas observaciones y estilo barroco, las mismas cuestiones sobre el estómago, el paladar y la masticación; si bien destacando la indigestión, como se ha visto anteriormente, como cuestión central. ${ }^{38}$

Quizas el párrafo que mejor resume Peptic Precepts es el concepto que Kitchiner tiene de la estructura del cuerpo humano; puesto que aunque sigue considerando que la víscera principal, según la mejor tradición aristotélica, es el corazón, el estómago no deja de ocupar una posición fundamental en esta jerarquía orgánica.

La estructura humana puede ser comparada con un reloj, dentro del que el corazón es el resorte principal, el estómago es el regulador y lo que se en él se introduce es la llave con la que se da cuerda a la maqui-

37 Kitchiner, William, The Art of Invigorating and Prolonging Life by Food, Clothes, Air, Exercise, Wine, Sleep, \&c. and Peptic Precepts, Printed for Hurst, Robinson, and CO. (London, 1821), pp. 158-161

38 «La indigestión o, por usar el término actual, un ataque de bilis - como sucede con frecuencia tras un sobreesfuerzo, o ansiedad de la mente como en el caso de alimentos refractarios - produce con frecuencia flatulencia y la flatulencia produce palpitación del corazón, que es muy difícil de parar cuando se produce una hora o dos después de una comida. El estómago parece incapaz de continuar con su trabajo al estar sobredistendido por el aire que presiona el corazón y los vasos sanguíneos mayores, obstruyendo la circulación. En el instante en que la flatulencia se disipa, todo vuelve a funcionar bien. Llene los pulmones al máximo, es decir, inhalando tanto aire como pueda y reteniéndolo todo el tiempo que pueda. Esto, algunas veces actuará como contrapeso y producirá alivio». Ibidem, p. 173. 
naria. Según la cantidad, la cualidad y la propia digestión de lo que comemos y bebemos, así será el ritmo del pulso y el funcionamiento del sistema en general. ${ }^{39}$

Es interesante destacar, en todo caso, la diferencia existente entre esta definición del cuerpo humano en la que el órgano principal es el corazón, mientras que en la definición incluida en The Cook's Oracle, este lugar central era ocupado - en lo que sin duda era una muestra más de la subversión romántica - por el estómago. ${ }^{40}$

\section{Los Ensayos morales, filosóficos y estomáquicos de Launcelot Sturgeon (1822)}

Pocos años después de la publicación de este libro, veía la luz en 1822 la obra Essays, Moral, Philosophical, and Stomachical, on the Important Science of Good-Living, obra eminentemente gastronómica de Launcelot Sturgeon. ${ }^{41}$ Mientras que las obras gastronómicas de Kitchiner se concebían más ceñidas al modelo tradicional del libro de cocina, la preocupación de Sturgeon es el apetito, no la cocina. Sturgeon se aleja por tanto del género del libro de cocina británico para situarse en la plenitud del modelo gastronómico. Al igual que Brillat-Savarin, Accum y otros gastrónomos, Sturgeon se identifica como «Miembro del Beef-Steak Club y de varios Pic Nics».

Los autores gastronómicos del siglo XIX británicos acostumbraban a ocultar sus nombres tras seudónimos como «The Epicure», «The Alderman» o incluso se jugó con términos como Kitchiner (cocinero); pero, cualquiera que fuese la identidad de Sturgeon (Charles Lamb o William Beckford), quizás lo más importante sea el seudónimo en sí y el contenido simbólico que evocaba. Lo que está fuera de toda duda es la enorme influencia que en la obra de Sturgeon tuvo Grimod de la Reynière. El esturión (sturgeon) era efectivamente el pez imperial del mar Caspio, apreciado ya por los romanos, y ofrecido en Gran Bretaña al rey como la más

\footnotetext{
39 Ibidem, p. 166.

40 «El estómago es el resorte principal de nuestro sistema» Kitchiner, William, The Cook's Oracle, p. 5.

${ }^{41}$ En este trabajo se utiliza la segunda edición, de 1823.
} 
preciada reliquia cuando se capturaba en sus aguas. ${ }^{42}$ La influencia de Grimod es tal en Sturgeon, que el ensayo «The Fatal consequences of Pride Considered on its Effects Upon Dinners» está copiada del Almanach des gourmands; su otro ensayo «On Mustard Philosophically Considered; and on the Use of Garlick as a Perfume»; también deriva de la obra de Grimod; y otro de sus trabajos «On the Nature and Properties of the Braise; with a Concise Account of its Origin» es una mera adaptación de un cuento también relatado anteriormente por Grimod. Por último, la primera página de su obra, grabada por William Hughes, es una copia de Les Meditations d'un gourmand, también diseñada por Grimod. ${ }^{43}$ Por si ello fuera poco, en la página del título, Sturgeon se declara Fellow of the Beef-Steak Club, and an Honorary Member of several Foreign Pic Nics. $\& c . \& c . \& c$; que, para Denise Gigante, aproxima a Launcelot Sturgeon a otros gastrónomos tales como Brillat Savarin y Frederick Accum, en su obra, Culinary Chemistry. ${ }^{44}$

En la introducción a su obra cabría destacar dos fragmentos en los que se vislumbra su verdadera naturaleza. ${ }^{45}$ En primer lugar Sturgeon, citando a Hume, distingue entre el epicureísmo y la gula, dos conceptos que la «gente ignorante», de malas intenciones o de apetitos débiles y envidiosos, solía confundir. ${ }^{46} \mathrm{La}$ referencia a la cocina y gastronomía francesa es,

42 Gigante, Denise, Gusto. Essential Writings in Nineteenth-Century Gastronomy, pp. 79-83. La obra consta de un total de diecinueve ensayos, que tratan de muy variados temas tales como la arquitectura de los comedores, las consecuencias físicas y políticas de las salsas, las cualidades morales del estómago, la mostaza considerada filosóficamente, el uso del ajo como perfume, las virtudes de la antigua familia de los cerdos, la filosofía del estómago, las cualificaciones de los cocineros, su salud física y moral, y finalmente, «doce reglas de oro dirigidas a las cocineras, que deberían estar expuestas en las chimeneas de las cocinas de todo el Reino».

43 Gigante, Denise, Gusto. Essential Writings in Nineteenth-Century Gastronomy, p. 82.

44 Ibidem, p. 79.

45 Como se ha visto, muchas obras culinarias iban dedicadas a personajes de la nobleza o de la monarquía. El caso de Launcelot Sturgeon es un tanto peculiar, ya que dedica sus Essays a los concejales de la City of London: «Dedicado a la distinguida Corte de los Concejales de la City of London». Sturgeon, Lancelot, Essays, Moral, Philosophical, and Stomachic, on the Important Science of Good-Living, a2, iv.

46 «Cuando una dama le dijo a Hume que había oído que era un gran epicúreo, el historiador le respondió: "No, señora. Yo soy sólo un glotón”. La glotonería es, en realidad, un mero esfuerzo del apetito mediante el cual el más tosco engullidor de bacon de Hampshire alardear con el más distinguido consumidor de tortuga en una corporación. Sin embargo, el epicureísmo es el resultado de el "más selecto don del Cielo", un gusto refinado y discriminante. Éste es el atributo peculiar del paladar, aquél el del estómago». Ibidem, B2. 
por otra parte, digna de destacar en una obra publicada por primera vez en 1822; momento en el que el proceso de penetración de la cocina francesa en Gran Bretaña estaba en su punto crítico; y no en vano Sturgeon cita el Almanach des Gourmands mostrando la influencia evidente que en su obra tuvo Grimod. ${ }^{47}$

Tras la breve introducción sigue un capítulo titulado «Moral Maxims and Reflections» en los que se condensa el pensamiento gastronómico de Sturgeon, no desprovisto de cierta ironía. El buen gastrónomo, afirma, no puede olvidar que comer es el objeto de la vida. ${ }^{48}$

Lo que se sostiene en esta parte de la obra, resume bien puntos que ya conocemos de la concepción romántica de la gastronomía. Efectivamente, en estas páginas se reivindica la puntualidad en tonos enérgicos, se hace gala de un espíritu práctico muy próximo a la mentalidad empirista - se burla por ejemplo del temor a las supersticiones como la presencia del número trece en la mesa, o al mal presagio de derramar sal sobre ella- y destaca la comida, otra vez, como centro de atención del banquete relegando la atención hacia las mujeres hasta el momento del postre. Por supuesto, deben evitarse a toda costa las malas cenas, y previene acerca de los malos efectos del vino nuevo, las cenas con familiaridad y los conciertos interpretados por aficionados. No descuida, en fin, tal y como era de esperar, las bases fisiológicas de la digestión, el cuidado del estómago y las prevenciones acerca de la indigestión. ${ }^{49}$

Una vez finalizadas estas máximas y reflexiones, comienzan los ensayos, diecinueve en total, y que constituyen un singular tratado a medio camino entre el manual de urbanidad en la mesa, la reflexión filosófica y la exposición de los principios gastronómicos y culinarios. Aproximadamente una tercera parte, los 6 primeros, tratan de las cualidades del anfitrión y del orden, desarrollo y condiciones de los banquetes.

En los dos primeros se abordan las características del buen anfitrión y su repertorio de buenas maneras en el banquete. El texto destaca su figura como el papel más importante que un hombre pueda desempeñar en este mundo; aunque su capacidad en este sentido no dependa en absoluto

47 «Una estancia ocasional en París durante una gira gastronómica por el Continente nos ha capacitado para apreciar los méritos auténticos de la cocina y de los vinos franceses, y a seleccionar en el Almanach des Gourmands esas preciosas recetas que puedan particularmente estimular las capacidades de los apetitos discriminantes». Ibidem, p. 10.

48 Ibidem, p. 12.

49 Ibidem, pp. 14-19. 
del dinero. ${ }^{50}$ Con sentido del humor, e incluso sarcasmo, pone ejemplos de lo que no se debe hacer para demostrar urbanidad y buenos modales ubicando al personaje en situaciones ridículas.. ${ }^{51}$ Sostenía por ejemplo que en un banquete era muy importante dirigir la mirada al lugar adecuado, y especialmente si se tenía un ojo de cristal, lo que de todos modos proporcionaba al parecer un porte elegante y una gran distinción. ${ }^{52}$ Recomendaba también no gesticular en una conversación con el cuchillo en la mano; y proceder con precaución en el trinchado, poniendo cuidado en que un ave no aterrizase en el regazo de una dama, en cuyo caso se debía reaccionar con gran estoicismo. ${ }^{53}$

En cuanto a los cuatro ensayos siguientes, los dedicados a la disposición y ordenamiento de los banquetes, en cada uno de ellos, Sturgeon establece una o varias cuestiones cruciales, alrededor de las que gira todo el artículo. En el caso del epígrafe dedicado a «La teoría y práctica de las tácticas relativas a los banquetes» - con un título que ya sugiere una estructuración inspirada en el ordenancismo militar - el argumento central es el carácter indispensable del banquete en el conjunto de todas las cuestiones vitales del hombre. ${ }^{54} \mathrm{El}$ alto valor social que se otorga a estas reu-

50 «Es, en realidad, mucho más fácil adquirir una fortuna rápidamente que aprender a gastarla científicamente. Para llegar a ser un auténtico anfitrión, un hombre debería pasar por todos los títulos, desde aficionado a los banquetes (B.A. or amateur of banquets) hasta dador de comidas ( D. D. or donor of dinners). Debería, además, tener un talento natural para comer, no un apetito indiscriminado de ternera y cordero que pertenece a lo vulgar, sino esa delicadeza del paladar que es el atributo del auténtico genio». Ibidem, p. 24.

51 «Cuando se ha anunciado la cena y si usted sigue a una dama hacia el comedor, no pise su cola ni dé un paso atrás para evitarla pisándole un pie. Y si le tuviese que conducirla a su asiento, esfuércese en no caerse sobre las sillas en su prisa por acomodarla en su sitio». Ibidem, p. 30.

52 «Una vez sentado, no se quede mirando a las lámparas como si fuese un lampistero calculando su contenido, sino que mire con curiosidad alrededor de la mesa como si tuviese un ojo de cristal que, de paso, es de gran ayuda para la cortesía. Aplíquelo fijamente sobre el objeto más próximo, pues los que están más lejos no requieren tal ayuda». Ibidem, p. 37.

53 «Sin embargo, si ocurriese un accidente, no se excuse ya que las excusas son sólo un reconocimiento de la torpeza. Recordamos haber visto a un hombre muy puesto a la moda depositar un pavo en el regazo de una dama. No obstante, con admirable compostura y sin ofrecer la más mínima disculpa, terminó una historia que estaba contando y, volviéndose a ella, simplemente dijo: "Señora, le agradecería que me pasase ese pavo"». Ibidem, p. 40.

54 «En resumen, una coqueta renunciaría al placer de ser admirada, un poeta a ser alabado, un sastre a engañarte, un dandy a endeudarse, un clérigo a sus diezmos y los abogados y médico a sus minutas, un alguacil te dejaría irte sin un soborno. Todos harían eso, pero siete octavos de los habitantes de Londres no renunciaría a un buen banquete». Ibidem, p. 47. 
niones explica por qué en el siguiente ensayo, el titulado «Sobre la naturaleza, la intención y el valor de las invitaciones» - en realidad, una adaptación de «L'importance des Invitations» en el Almanch des Gourmands de Grimod - se elogie la largura desplegada en el convite, criticando la escasa sinceridad de algunos anfitriones que, fieles a su tacañería, escatiman al invitado toda clase de placeres de la mesa. ${ }^{55}$ En la parte dedicada a «Las fatales consecuencias del orgullo considerando sus efectos en los banquetes», a su vez, es igualmente directo en sus consideraciones. Comienza con el proverbio, «se come más con los ojos que con el estómago», y sin despreciar la elegancia que supone una disposición simétrica de los platos y ornamentos en la mesa, Sturgeon se queja sin embargo de que éstos, al ser servidos simultáneamente por mor de la estética, se quedan fríos. ${ }^{56}$ En fin, en el último de los ensayos que ahora estamos considerando, «Sobre la arquitectura moderna y las miserias y comodidades comparativas de los comedores», Sturgeon se queja a su vez de que los comedores de los hogares de Londres se encuentran situados en el lugar más ruidoso de la casa, con techos bajos, demasiado cerca del fuego de la chimenea y, víctimas de la simetría, próximos a las puertas que molestan a los comensales. ${ }^{57}$

Pero quizás la parte central del trabajo de Sturgeon se condense en los 8 ensayos centrales - desde el número siete al catorce - donde, sin abandonar nunca su peculiar retórica literaria, se ocupa de las salsas y condi-

55 Ibidem, pp. 62, 63.

56 [Pope]. Ibidem, p.72.

57 «Imaginémonos ahora un comedor dispuesto de esta manera, bien calentado y alfombrado, muebles púrpura, luz de lámparas, la mesa cercada por una amplia mampara, sillas con apoyabrazos, profundas, con la tapicería bien rellena, no más de diez comensales, ni más de dieciséis platos (excluyendo las sopas, las verduras, los acompañamientos y el postre) y éstos servidos aparte. La comida caliente, los vinos frescos, el apetito ávido y el estómago limpio. La imaginación apenas puede concebir una idea de felicidad humana que exceda tal escenario y aquél que lo pueda hacer realidad nunca envidiará las dichas del paraíso».

«Que los tapices cubran las paredes del salón,/ Y los acogedores banquetes sean servidos en comedores bien caldeados,/ Que los suelos se cubran con alfombras de Turquía,/ Que sobre las mesas se extienda el damasco más blanco,/ Que los aparadores brillen con ingentes cantidades de enormes platos,/ Que las jarras de cristal están repletas de vinos generosos, /Así festejan los Dioses que cenan en el Olimpo». [Virgil, Aeneid VII]. Ibidem, p. 78. Sturgeon, de acuerdo con un recurso que ya conocemos, busca además aquí refrendar su argumentación con la autoridad de La Eneida, de Virgilio, de la misma manera que en el anterior ensayo citaba a Alexander Pope. 
mentos primero, de los asados de buey y de cerdo más tarde, y luego de las principales comidas y bebidas que amenazan la digestión correcta del banquete; coronado con unos cafés y licores a los que se dedica otro ensayo. El último de este bloque de capítulos se dedica íntegramente al arte de los estofados.

Sturgeon, no hay duda, considera que son las salsas el elemento fundamental de un buen plato, y lo que le confiere su toque final, similar al retoque último de un pintor o al maquillaje de una mujer hermosa. El maridaje de sabores y texturas de las salsas sirve en todo caso de pretexto para que, en el ensayo octavo, se aborde la cuestión general de las good connexions y sus distintos ámbitos sociales (familiares, matrimoniales, ilícitas, políticas o comerciales), lo que permite reconsiderar la estructura y composición de las salsas. ${ }^{58}$

Los asados de cerdo y buey consumen a su vez otros dos entusiasmados e ingeniosos ensayos, aunque seguramente el dedicado al buey - el décimo - sea más jugoso por sus derivaciones nacionalistas y por la forzada síntesis que se realiza entre la vieja sabiduría inglesa de los asados, y los refinados preceptos de la gastronomía francesa. Incluso el patriótico emblema del chauvinismo culinario británico, «The Roast Beef of Old England», puede ser mejorado, se dice, gracias al arte culinario francés. Según Sturgeon, el modo inglés de asar bien una pieza de ternera desperdicia los invaluables jugos y, para evitar este desastre, el remedio es muy sencillo: sumergir la carne en sebo, immersing the joint in rendered tallow. ${ }^{59}$ Sturgeon, muy a su pesar, reconoce en conclusión la superio-

58 «El deber de una Buena salsa es titular las extremidades capiálcelas de las glándulas maxilares y así adular y excitar al apetito. Si la salsa es demasiado suave, no produce sensaciones y no consigue su objetivo; y si es demasiado pungente, en lugar de despertarla, excoria la suave estimulación del paladar». «El arte de componerlas es uno de los grandes misterios de la ciencia y su logro es el mismo pináculo del arte culinario. Sus elementos son verdaderamente sencillos, consistentes principalmente en gravy o nata, al igual que las relaciones de interés o de afecto. Su objeto, también, es cimentar la unión de cualidades, a la vez variadas y discordantes. Al igual que en un matrimonio feliz, en los intereses, en el humor y en los deseos, cada uno debe ceder ante el otro con el fin de alcanzar la armonía, que es la base de la felicidad conyugal y del orden social; de esta misma manera, en un buen ragoût, la substancia, el condimento y la salsa deben estar todos fundidos en esa exquisita concordia que constituye la base de la buena cocina y de todo disfrute racional». Ibidem, pp. 81, 88 y 89 .

59 Ibidem, pp. 106-108. Entretanto, el ensayo número nueve, «Sobre la mostaza considerada filosóficamente y sobre el uso del ajo como perfume» se compone principalmente de dos odas a cada uno de estos dos condimentos. 
ridad culinaria del enemigo francés, que fue capaz de asaltar victoriosamente la fortaleza más preciada de la cocina británica, al asado. ${ }^{60}$

En todo caso, y tras abordar en otros ensayos los ingredientes dañinos para el estómago (las espinas, las comidas demasiado calientes...) y ensalzar el café y los licores como restauradores balsámicos de los estómagos cansados, todavía tiene tiempo para dedicar otro capítulo a la sabiduría de los lentos estofados; y aderezándolo además con disquisiciones históricas muy propias, como se ha visto, de la época. Sturgeon, efectivamente, atribuye aquí a Monsieur Le Gacque su invención cuando, en un examen culinario preparó un pavo estofado que un jurado de París, Constitucional Association, consideró excelente en comparación con otros dos pavos, uno cocido y otro asado. ${ }^{61}$

Ahora bien, con ser muy importantes estos capítulos centrales del libro, dado que abordan su meollo, esto es, la comida, no es menos cierto que la obra dejaría de ser un producto típico de su época si no se considerara, de una parte, lo que como ha podido comprobarse es su peculiar y especialísima envoltura literaria; y de otra, el conjunto final de 5 ensayos - del decimoquinto al decimonoveno - que suponen abordar la base digestiva y fisiológica de la cocina, lo que la emparenta inmediatamente con la Fisiología del gusto de Brillat-Savarin, así como la docencia y el equipamiento infraestructural y humano (las cocineras) de la elaboración de los alimentos.

Efectivamente, en sendos ensayos analiza el funcionamiento del estómago, así como el de los dientes; para pasar acto seguido a argumentar la necesidad de que se enseñasen en las escuelas conocimientos de cocina, ayudándose de reglas nemotécnicas que él mismo compendiaba.

En el conjunto de este último bloque de ensayos, es significativo asimismo que en el penúltimo se establezca una comparación entre las gestas gloriosas de armas y un banquete excelente. Los cocineros deben ser ensalzados y felicitados de la misma manera en que un militar es galar-

60 «Al presentar esta receta en nuestro país como un objeto de verdadera importancia nacional, todavía tenemos que lamentar que el mérito de su descubrimiento corresponde a Francia. Tenemos que confesar que manifestamos este reconocimiento con cierto grado de confusión - nos sentimos como invadidos, por así decirlo, en nuestro propio territoriocuando el baluarte del roast-beef era exclusivamente nuestro...»Ibidem, p. 108.

61 Tras el triunfo del estofado, el jurado registró en su libro de actas:

«Turkey boil' d/ Is turkey spoil'd,/ And turkey roast/ Is turkey lost; -/ But, for turkey braised,/ The Lord be praised!» (Pavo hervido es pavo estropeado, y pavo asado es pavo perdido. Sin embargo, si el pavo es estofado, el Señor sea loado) Ibidem, p. 155. 
donado por un acto heroico. Para ilustrar esta comparación, Sturgeon relata una breve biografía de Charles Augustus Armand Vatel, inventor del glorioso plato Côtellettes à la Maintenon y del catsup, o actual ketchup. ${ }^{62}$ La comparación no era absurda; la organización de una cocina como la de Vatel exigía de una disciplina rigurosa y de una intendencia exquisita; lo que la aproximaba en sus principios a un arte como el de la guerra - respetable y plenamente considerado como tal en el siglo XVIII - y con el que se compara a todos los niveles la cocina. ${ }^{63}$

El último ensayo, el diecinueve, se ocupa fundamentalmente de la salud física de las cocineras, dado que al hallarse constantemente expuestas a los humos y al calor de los fogones, enfermaban con facilidad. Con su habitual sarcasmo, Sturgeon señala que, como gran parte de su labor consiste en probar con el dedo las salsas, de cuya óptima elaboración depende la excelencia de una cena, era necesario administrarles infusiones y algún emético (vomitivo) suave, sometiéndolas a una estricta dieta. La actitud sexista hacia estas damas, en contraste abierto con el sumo respeto y admiración que profesa a los chefs y cocineros, se percibe claramente en el autor.

Aunque no profesamos una admiración ardiente hacia esa parte del sexo débil que se dedica a los cuidados de la cocina - su savoir-faire en ese arte nunca en nuestra estimación se puede equiparar al de sus maestros y rivales masculinos - sin embargo, es a veces nuestro sino cenar en hogares donde sólo ellas están empleadas y no podemos evitar sentir cierto grado de interés en su bienestar. Por tanto, exponemos que no se puede concluir una obra de carácter moral cono esta sin la inclusión de algunas máximas que rijan su conducta que nos han sido comunicadas por la verdaderamente respetable asociación «LA SOCIEDAD PARA LA SUPRESIÓN DEL VICIO».64

${ }^{62}$ El cocinero, ante la dificultad de obtener buen pescado en el entorno de París, encargó a un mensajero que se lo trajese fresco de un puerto de mar, pero el mensajero se emborrachó y Vatel se quedó sin pescado y, ante la imposibilidad de preparar los cuarenta y ocho platos de pescado que había prometido a un príncipe que celebraba un banquete al día siguiente, se quitó la vida clavándose una broqueta en el corazón. De esta manera, Vatel es situado en una posición heroica, como mártir, en el campo de batalla de la cocina. Ibidem, pp. 195-201.

63 Sobre la evolución del arte de la guerra recuérdense las aportaciones tácticas de Mauricio de Sajonia (1757) y Federico II de Prusia (1747). Sobre Vatel puede consultarse la biografía de D. Michel, Vatel ou la naissance de la gastronomie, Fayard (París, 1999).

${ }^{64}$ Ibidem, pp. 207, 208. 
De estas reglas se ocupa en el último capítulo de la obra, «Twelve Golden Rules for Women-Cooks», cargadas de ironía y de su habitual sentido del humor, y que según Sturgeon deberían ser expuestas en todas las cocinas del reino. ${ }^{65}$

La conclusión de Essays, Moral, Philosophical, and Stomachical, finalmente, consistía en el relato de un banquete celebrado en la casa del concejal Alltwist, en el transcurso del cual, varios comensales expusieron los nuevos avances tecnológicos aplicados a la cocina y a la mesa, en medio de insólitos acontecimientos. ${ }^{66}$

\section{Literatura y romanticismo gastronómico en la Inglaterra de principios del siglo XIX}

Ahora bien, por destacables que fuesen libros como The Cook's Oracle o los conocidos Essays, Moral, Philosophical, and Stomachical, de Launcelot Sturgeon, lo cierto es que su éxito no se explicaba sino como

65 En realidad, se trata de trece reglas, pero Sturgeon dice utilizar la docena de los panaderos, lo que supone la adición de una regla más. De manera abreviada, estas reglas son las siguientes: 1) Nunca te emborraches hasta que se haya servido el último plato. 2) No te pongas impertinente, salvo que estés de mal humor y no lo puedas evitar. 3) No estés enfurruñada, salvo que tengas que preparar una cena. 4) Nuca estropees una pieza de carne, salvo que te hayan pillado en un renuncio. 5) Nunca tengas una cena preparada para la hora que te pidan, salvo que sepas que la familia no está preparada para ella. 6) Nunca reconozcas que no tienes razón, salvo que el diablo sepa que no lo puedes evitar. 7) No tomes rapé, salvo que estés mezclando un cocido o revolviendo la sopa. 8) Nunca te laves las manos hasta que hayas terminado de hacer las empanadillas. 9) Nunca avises de que vas a dejar el trabajo, salvo que estés segura de que le vas a causar un grave inconveniente a la familia. 10) Nunca cuentes historias de la familia para la que trabajas, salvo que éstos les hagan daño. 11) Nunca hagas trampas, salvo que lo puedas hacer sin que te descubran. 12) Nunca digas una mentira, salvo que puedas conseguir lo mismo diciendo la verdad, ni tampoco digas una verdad cuando una mentira te pueda favorecer más. 13) Nuca mantengas un enamorado fuera de la casa, salvo que no puedas mantenerlo dentro de ella. Ibidem, pp. 211, 214.

${ }^{66}$ El primero de estos inventos peregrinos (gadgets) consistía en un aparato que abría las ostras, permitiendo que llegasen vivas al estómago; el segundo se trataba de unos tractores galvánicos que ayudaban a las mandíbulas a masticar mejor; luego venía un método de matar los pavos mediante electricidad, en lugar de colgarlos de la cola hasta que perdiesen todas las plumas; un procedimiento para aplicar gas al estómago con el fin de aumentar su capacidad y en último lugar, una salsa universal, adecuada a todos los paladares pero que no recibe la aprobación de los comensales. La velada finalizó de una forma un tanto mágica, puesto que al intentar reparar una pluma que estaba en una mesa, ésta se convirtió en mondadientes que todos los comensales utilizaron. 
partes integrantes de un movimiento más amplio. Un año después de la obra comentada de Sturgeon, vio la luz el trabajo de uno de los más notables gastrónomos de la época, Charles Lamb. Resulta extraño que este escritor romántico nunca haya sido leído en el contexto del género gastronómico que surgió en Gran Bretaña a partir de la década de 1820 aunque, con toda certeza, fue influido por él al igual que otros escritores de similar estilo. Lamb publicó su «A Disertation Upon Roast Pig» tras regresar de un viaje a Francia con su hermana Mary, impresionado por lo deliciosas que habían sido las ranas que había comido en el país vecino, en comparación con la monotonía de la dieta de su país.

Lamb era admirador del cocinero romano Apicius y de Heliogábalo, a quien elogia por haber iniciado la utilización de sesos de ruiseñor y lenguas de pavo real como guarnición; el detalle ilustra la erudición del autor en la materia, y su apertura y capacidad de incorporar sin prejuicios la variedad presente en otras cocinas y épocas. El estudioso Fred V. Randel afirmaba que, en la práctica, todos los ensayos de Lamb hacen referencia de uno u otro modo a la comida o a la bebida, habiendo recopilado una impresionante lista de alimentos mencionados por su personaje ficticio Elia. ${ }^{67}$

«A Disertation Upon Roast Pig» se publicó por primera vez en Londres en 1823, y relata la historia de un personaje chino, Ho-ti, cuyo hermano menor quemó su casa y la adyacente cuadra de los cerdos por accidente. Ho-ti y su padre probaron la piel asada de uno de los cerdos y la encontraron exquisita. Por accidente, habían descubierto un nuevo manjar, el crackling. Al extenderse el rumor de la excelencia del crackling, todas las casas de la aldea comenzaron a arder, por lo que Ho-ti fue juzgado, pero absuelto cuando el jurado probó el delicioso manjar. Tras el juicio, las casas de los miembros del jurado también aparecieron en llamas. ${ }^{68}$

El ensayo está salpicado de referencias a Coleridge, Rabelais y Milton y, al final de la historia Charles Lamb - en un nuevo gesto de traición al inveterado culto británico a los animales - exhibe una clara tole-

67 En una carta dirigida a Samuel Taylor Coleridge, Lamb elogia la suculencia del cerdo asado, así como de varios tipos de pescado: el abadejo, el rodaballo y el John Dory o St. Peter's fish. Noon Talfourd., Thomas, The Works of Charles lamb, Harper \& Brothers (Ney York, 1838), pp. 197, 198.

68 Lamb, Charles, «A Dissertation Upon Roast Pig», en Essays of Elia, William Veazie (Boston, 1860), p. 208. 
rancia hacia la muerte del cerdo por flagelación, con el objeto de hacer su carne más tierna. ${ }^{69}$

En otro de sus ensayos «Grace before Meat», publicado por primera vez en 1821, de nuevo citando a Milton, Coleridge, Horacio y Samuel Johnson, Lamb desaprueba el hecho de dar gracias a Dios por los alimentos que se hallan sobre la mesa. Utilizando referencias a cuáqueros y metodistas, argumenta que el momento en el que se siente apetito es el menos indicado para manifestar gratitud. ${ }^{70}$

Aproximadamente hacia los mismos años en que se editaban las obras de Kitchiner, Sturgeon y Lamb, en la segunda década del siglo, se hacía pública también la obra de Dick Humelbergius Secundus. El seudónimo Humelbergius es una alusión al anotador de Apicius, Gabriel Hummelberger, que editó el décimo libro sobre especies y condimentos de Arte Coquinaria en 1542. Dick Humelbergius Secundus se compara a sí mismo con el cocinero que deriva sus ingredientes de otras partes y que, por tanto, es un mero recopilador del material de otra gente, que utiliza para compo-

69 «Leemos sobre los cerdos azotados hasta la muerte con una especie de horror, igual que si escuchamos cualquier otra costumbre obsoleta. La edad de la disciplina es tiempo pasado, o sería curioso preguntar (meramente bajo la luz filosófica) qué efecto podría esto tener si se hace con el fin de dulcificar o hacer más tierna una substancia ya tan dulce y tierna en su estado natural, como es la carne de los cochinillos. Es como si se pretendiese refinar una violeta. Sin embargo, deberíamos ser cautos al condenar la humanidad y al censurar la sensatez de esta práctica. Podría proporcionarle gusto». Ibidem, pp. 208-209.

70 «En ocasiones, (rarus hospes) cuando me he sentado a la mesa de hombres ricos ante la sabrosa sopa, con el vapor de los platos humeando y penetrando en nuestro olfato y humedeciendo los labios de los invitados con el deseo y una distraída variedad de platos, he percibido que la introducción de tal ceremonia es extemporánea. Con el orgasmo devorador ente ti, parece impertinente interponer un sentimiento religioso. [...] Los calores del epicureísmo apagan la suave llama de la devoción. El incienso que surge alrededor es pagano y el dios del vientre lo intercepta por su propio bien. El propio exceso de provisión, más allá de las necesidades, hace desaparecer la proporción entre el fin y los medios. El dador está velado por sus dádivas. Tú te sobresaltas ante la injusticia de devolver las gracias - ¿por qué? - por tener demasiado mientras tantos pasan hambre. Es alabar a los dioses erróneamente». Lamb, Charles, Essays of Elia, Baudry's European Library (Paris, 1835), p. 101. Se puede observar en estas líneas cierto parecido con la prosa de Launcelot Sturgeon, lo cual añadido a las observaciones de Denise Gigante, puede reforzar la hipótesis de que Charles Lamb fuese, en realidad, le persona que se ocultase detrás del seudónimo Launcelot. Para Gigante, el hecho de que ambos consideren que el cerdo es un miembro más de la sociedad, el hecho de que confundan los cerdos con los humanos y que ambos utilicen la palabra gusto, son pruebas, aunque no concluyentes, de esa identidad. Otra posibilidad sobre la identidad real de Sturgeon, apuntada por Gigante, es William Beckford. Gigante, Denise, Gusto. Essential Writings in Nineteenth-Century Gastronomy, p. 82. 
ner sus platos más deliciosos. Su libro, Apician Morsels fue el texto gastronómico más conocido tanto en Estados Unidos. como en Inglaterra durante el siglo XIX. ${ }^{71} \mathrm{Al}$ igual que Apicius Redevivus de Kitchiner, el título Apician Morsels alude al chef romano Apicius Coelius que escribió sus propias recetas preservando así la gloria de la gastronomía romana para los siglos venideros. Los «morsels» recopilados por Humelbergius incluyen exquisiteces de Grimod de la Reynière y de Brillat-Savarin, organizados, de todos modos, en categorías culinarias tales como: «Code of eatics», «Epicurean Precepts» y «Nutritive Maxims, Reflections, Anecdotes». El tono, reflexivo, filosófico y literario domina aquí también, por tanto, en lógica coherencia con los presupuestos de la literatura gastronómica de la época. ${ }^{72}$

Apician Morsels fue publicado en Londres en 1829 y consta de 25 capítulos, cada uno de los cuales constituye un «bocado» de Apicio. En los primeros cinco capítulos trata de las comidas de los romanos, ciertamente, pero más adelante la obra se torna más romántica en temas y en estilo.

El primer ensayo que se adhiere a las tendencias estilísticas y temáticas de las obras románticas es el número seis, «Stomach and Appetite», en el que compara al estómago con las gaitas escocesas y analiza el apetito desde el punto de vista gastronómico. ${ }^{73}$ De entre los varios tipos de apetito, el autor está interesado en el que proporciona placer y que se obtiene particularmente mediante unos platos bien preparados; se trata por tanto de un placer proporcionado artificialmente y no del que se deriva de

${ }^{71} \mathrm{Al}$ igual que con la identidad de Sturgeon, Denise Gigante especula con la posibilidad de que el autor de Apician Morsels sea William Beckford, o también el escritor irlandés de origen francés Richard Chenevix.

72 Nótese el juego de palabras en inglés entre eat (comer) y ethics (ética), mediante el cual «Code of eatics» podría traducirse como «código de una ética de la comida».

73 «Por tanto el estómago, considerado anatómica y fisiológicamente, y en ausencia de un símil mejor, puede ser comparado inapropiadamente con un par de gaitas escocesas que, al tener una entrada y una salida para el aire que deberían recibir y contener, al no ser distendidas más allá de su elasticidad natural, cumple sus funciones con facilidad y armonía». «Según los gastrónomos, hay tres clases de apetito, dos de ellas aparecen inmediatamente ante la consideración del gourmand:

1. El apetito que sentimos en un estómago vacío...

2. El apetito que se siente cuando, sentados en una cena sin tener hambre...

3. El apetito que excita alguna vianda delusiva que aparece al final de la comida cuando, una vez satisfecho, el hombre mesurado está a punto de retirarse sin renuencia. Esto puede ser tipificado por los soeces deseos del libertinaje que, aunque ilusorios, o alimentándose únicamente en la mente, proporcionan sin embargo algunos placeres auténticos». Humelbergius Secundus, Dick, Apician Morsels; or, Tales of the Table, Kitchen, and Larder, Whittaker, Treacher and Co. (London, 1829), pp. 88-90. 
la satisfacción de necesidades fisiológicas primarias como la de «llenar el estómago» o saciar la simple hambre imperiosa.

En el capítulo número ocho, «Cookery and Poetry», se comparan además diversos géneros literarios con los banquetes. Por ejemplo, una buena comida es hermana de un buen poema; con una sola diferencia: entre las cuatro y las cinco de la tarde, el banquete es más sustancioso. ${ }^{74} \mathrm{En}$ una nueva y arquetípica concesión a la comicidad, en el capítulo diez, «A Short Dissertation on the Origin of Dentiscalps, or Toothpicks», se demuestra, en tono cómico, que el mondadientes es un invento de los egipcios, que habían observado cómo el icneumón (ichneumon) limpiaba los dientes del cocodrilo del Nilo. ${ }^{75}$

«The Knotty Point», título del capítulo once adopta a su vez un tono más decididamente especulativo, planteando la cuestión filosófica de si se vive para comer o se come para vivir; sin poder dar fácil solución al dilema, Humelbergius justifica ambas afirmaciones que, aduce, se pueden producir simultáneamente en una misma persona. Literatura y filosofía trascienden, por tanto, la dimensión física del puro comer. ${ }^{76}$ No obstante el recurso a lo cómico se recupera con facilidad, y en el capítulo catorce se aporta en esta línea un listado de desgracias que le ocurren con frecuencia a las personas que salen a comer fuera de casa, «Personal Vexations; or, the Miseries of Dining Abroad, as Well as at Home», recuerdan a una especie de catecismo de las leyes de Murphy. Se trata de un listado de treinta y cinco calamidades que pueden ocurrir a cualquiera en los ámbitos de la gastronomía y de la hospitalidad. Humelbergius espera que éstas sirvan de consuelo al lector, puesto que dada su magnitud, empequeñecen las que normalmente suelen ocurrirle a éste en su vida diaria. ${ }^{77}$

74 «un buen banquete es como un buen poema, con la única diferencia de que el primero es más substancial entre las cuatro y las cinco». Ibidem, p. 105.

75 Ibidem, pp. 141, 142.

76 «El hombre mesurado adopta el primero, el hombre de apetito, el Segundo. Ahora bien, como hay pocas gentes del país, vocación o secta que sea que no preferirían una buena cena a una indiferente y una de cualidad indiferente a ninguna en absoluto, mantenemos que es casi tan racional para un hombre vivir para comer como comer para vivir». Ibidem, p. 150.

77 La desgracia número uno consiste en perder la llave y tener que llamar al cerrajero, la segunda desgracia es tener que afeitarse con agua fría o verse obligado a bajar las escaleras cuando el sirviente las está barriendo. En la mayoría de los contratiempos hay un componente humorístico «VII. Al llegar al salón donde están reunidos todos los invitados, saludas al anfitrión y le diriges elegantes cumplidos a la señora de la casa. Después te sientas precipitadamente en un sillón y estás a punto de matar al gato que unos minutos antes había sido cubierto de caricias». Ibidem, p. 297. 
Iniciada la década de los años treinta, en todo caso, otros libros gastronómicos iban a proseguir la saga iniciada una década atrás. Aunque «Aristology, or the Art of Dining» no fue el único tema tratado en su volumen The Original, sí fue sin duda, el trabajo más popular de Thomas Walker. Su publicación semanal comenzó en mayo de 1835 y, hasta diciembre de ese mismo año, vieron la luz veintinueve ejemplares. En el último número, Walker afirmaba que escribir y vivir en Londres no era una buena combinación ya que la consecuencia eran múltiples invitaciones que constituían un signo gratificante de aprobación, pero de ruinosas consecuencias para la salud. ${ }^{78}$

La primera parte de «Aristology, or the Art of Dining» se publicó en Londres el miércoles, doce de agosto de 1835 en lo que constituyó el primero de una serie sucesiva de ensayos que fueron apareciendo en las semanas posteriores. En las primeras líneas Walker define lo que es la aristología y los tipos de comidas que existen y, al igual que otros gastrónomos románticos, insiste en la puntualidad como una de las obligaciones de los comensales. ${ }^{79}$

Este primer número de The Original está dividido en varias partes: «Aristology, or the Art of Dining», «Preferment to Place», «Poverty and Pauperism», «Temper» «Letters from the Continent»y «Sayings». En el número siguiente, publicado el 19 de agosto del mismo año se incluye un artículo, «Domestic Economy of the Labouring Classes» en el que se analiza con muy buen criterio las lamentables condiciones de vida de las clases trabajadoras. «On Attendance» es la continuación de «The Art of Dining», fragmento en el que Walker se lamenta de los excesivos e innecesarios servicios en la mesa. ${ }^{80}$

No faltan, como era habitual en la época, las alusiones sexistas, como cuando se enfatiza la falta de realismo de las damas que se sientan a dis-

78 Véase, Gigante, Denise, Gusto. Essential Writings in Nineteenth-Century Gastronomy, p. 205.

79 «Según el Lexicón, el término griego que define la comida es Ariston y por tanto, para conveniencia de los términos y para no entrar en ningún tipo de investigación crítica o de antigüedad del término, yo llamo Aristología al arte de comer y Aristólogos a aquéllos que la estudian... Hay tres tipos de comensales: solitarios, comensales sociales cotidianos, y comensales de grupo. Los tres tipos abarcan la consideración de la aclamación y los dos últimos, también de la sociedad... Si el contento debe ser un acompañante de todas las comidas, la puntualidad es esencial y por tanto, el comensal y la comida deberían estar preparados al mismo tiempo». Walker, Thomas, «Aristology, or the Art of Dining», en The Original, Henry Renshaw (London, 1835), pp. 189-190.

${ }^{80}$ Ibidem, pp. 225, 226. 
frutar de un banquete, en contraste con el sentido común exhibido por los caballeros:

Los caballeros se mantienen más vigilantes de las cuestiones económicas reales, mientras que las damas se concentran principalmente en la exhibición y el adorno, o en la forma y la ceremonia - si bien no todas, porque algunas poseen unas excelentes nociones del gusto y del confort y el cultivo de éstas debería ser una de las principales características de este peculiar género para el gobierno del hogar. ${ }^{81}$

En la década de los años cuarenta, finalmente, todavía se editaron algunos libros más de temática gastronómica, como los de William Makepeace Thackeray y The Alderman. El primero de ellos escribió su mejor retrato de la esnobista alta clase social en la Inglaterra de la Regencia en Vanity Fair, publicada en series entre 1847 y 1848. Por las mismas fechas, también colaboró con la revista popular Punch satirizando un amplio conjunto de snobs: «Royal Snobs», «Irish Snobs», «Military Snobs», «Clerical Snobs», «Literary Snobs», «Party-giving Snobs», «Continental Snobs», etc. El conjunto de sus semblanzas fue publicado en 1848 en un volumen titulado The Book of Snobs. ${ }^{82}$

El narrador de Thackeray se dirige familiarmente a un personaje al más puro estilo de John Bull, llamado «Jones», que también aparece en Vanity Fair al lado de una jarra de vino y una pata de cordero. Jones es un reflejo ficticio del autor en primera persona de The Book of Snobs y considera los dinner parties victorianos y su mentalidad de clase media, en cuanto a guardar las apariencias, como algo absolutamente esnobista. Ésta es, en realidad, la cuestión fundamental de la obra de Thackeray; quien no desaprovecha la ocasión para alabar a su amigo Alexis Soyer por compartir con él sus opiniones sobre los esnobistas y recomendar las cenas caseras de su Regenerator. ${ }^{83}$

81 Ibidem, p. 248.

${ }^{82}$ En este trabajo se utiliza la edición de 1856.

83 «Si las cosas si hiciesen como yo deseo, la costumbre de dar cenas aumentaría al mismo ritmo en que debería disminuir el esnobismo que forma parte de ellas. Para mí, la parte más amistosa recientemente publicada por mi estimado amigo The Regenerator [Alexis Soyer] (si tras un breve conocimiento me permite que así lo llame), la constituyen aquellos pasajes que se refieren, no a los grandes banquetes y comidas ceremoniosas, sino a sus "comidas en casa"». Thackeray, William Makepeace, The Book of Snobs, Bradbury and Evans (London, 1856), p. 71. 
El intento de aparentar riqueza y la lucha de los snobs por simular una posición más alta que la que realmente ostentan a través de una actitud pretenciosa de dinner-giving, se puede percibir en la metáfora de Thackeray a este propósito, construida utilizando las ostentosas plumas de las colas de los pavos reales.

Los arrendajos con plumas de pavorreal son los esnobs de este mundo y, nunca desde los tiempos de Esopo han sido tan numerosos en tierra alguna de lo que lo son en este país libre. ¿Cómo se aplica este antiguo apólogo al sujeto que nos ocupa - el anfitrión esnobista de banquetes - ? La imitación del poderoso es universal en esta ciudad, desde los palacios de Kensingtonia y Belgravia, incluso hasta el más remoto rincón de Brunswick Square. Las plumas de los pavorreales están clavadas en las colas de la mayoría de las familias. Raro es entre nosotros el ave doméstica que no se pavonea imitando el grito desgarbado, chulesco y estridente de los gentiles. ¡Oh, confundidos anfitriones de los banquetes! ¡Pensad en cuánto placer os perdéis y cuánto daño causáis con vuestras absurdas grandiosidades e hipocresías! ${ }^{84}$

En fin, la obra de The Alderman, The Knife and Fork, Laid by the «Alderman». Founded on the Culinary Principles Advocated by A. Soyer, Ude, Savarin, and Other Celebrated Professors, with Fourteen Choice Cuts by Kenny Meadows, publicada en Londres en 1849, es un pequeño volumen dedicado a los concejales de la Corporación de esta ciudad. ${ }^{85}$

Estos ilustrados epicúreos, como los denomina su compañero, eran famosos por su banquete anual que se celebraba en Londres el Día del Alcalde. Se describe a estos caballeros como hombres de agrandados estómagos y distinguidos paladares, que recibirán con gran alborozo y calor cualquier obra referida a una cuestión de tan profunda importancia como la gastronomía.

El autor promete «dedicar el resto de mis días a la diseminación de claros principios gastronómicos contando con la colaboración de mis ca-

${ }^{84}$ El amplio título vertido al español es: El cuchillo y el tenedor, colocados en la mesa por el «Concejal». Basada en los principios culinarios advocados por Alexis Soyer, Ude, Savarin y otros aclamados maestros, con catorce selectas ilustraciones de Kenny Meadows.

Ibidem, p. 73.

85 Joseph Kenny Meadows, el ilustrador de la obra, era amigo de escritores gastronómicos, tales como Leigh Hunt, Douglas Jerrold, Charles Dickens y W. M. Thackeray. Gigante, Denise, Gusto. Essential Writings in Nineteenth-Century Gastronomy, p. 233. 
maradas concejales para salvaguardar la Constitución Británica a través de la provisión de gran cantidad de alimentos y la difusión del conocimiento de cómo cocinarlos de un modo valioso para una época en la cual vivimos para comer». El autor de Knife and Fork considera la gastronomía como una ciencia, y considera que el arte y la literatura ya han tenido su hora, siendo éste el momento de una nueva era gastronómica ${ }^{86}$

Como se puede observar, los temas de su obra son variados y, por tanto, abarcan cuestiones tan dispares como la adulteración de una exclusiva bebida, Kirchenwasser, o cómo los cerdos detectan las trufas. El estilo prosístico del anónimo Alderman se puede apreciar en el breve artículo «An Epicure's Oyster», en el que se lamenta de la ignorancia de los pescaderos quienes, con la buena intención de abrir las ostras para los clientes, matan el molusco.

La literatura gastronómica británica, en conclusión, a través de obras como estas, consiguió desplegar en la primera mitad del siglo XIX un conjunto de no poco interés. Para empezar, desmiente algunos tópicos acerca de la escasa cultura gastronómica inglesa, toda vez que en ese tramo temporal intentó una síntesis entre los refinamientos franceses, cuya superioridad generalmente era reconocida, y una tradición local potenciada por una revolución burguesa y en el consumo más temprana y de mayor profundidad que la francesa; lo que proporcionaba a la cocina insular un tono

86 «Los hombres sin apetito, con estómagos no mayores que una semilla de pasa pueden clamar contra la gastronomía, pueden despreciar a los epicúreos. Pero permítanme asegurarles que alzan sus voces y esgrimen sus plumas impotentes en oposición al progreso de la ciencia gastronómica. En los tiempos venideros, permítanme decirles que un caballero no será conocido por la moda de su vestimenta, sino por la capacidad de su estómago». The Alderman, The Knife and Fork for 1849, H. Hurst (London, 1849), p. 2. Tras esta reivindicación del advenimiento de una nueva era, presidida por la ciencia gastronómica, sigue una serie de capítulos que, bajo el título genérico de Hints to Gastronomic Students, tratan de temas, tales como: «Sobre la conducta general de los estudiantes», «Sobre la carne de ternera», «Sobre las setas», «Sobre la adulteración del Kirchenwasser (aguardiente de cereza)», «Reflexiones sobre las trufas», «Sobre los días de fiambre», «Sobre la influencia social y mercantil de las chuletas», «El horario del epicúreo», «Las copas del concejal», «Sobre tomar a la gente tal como es», «Un catecismo geográfico para estudiantes de Gastronomía», «Cómo mantener vivo el pescado», «Una taza de café», «Sobre el tratamiento hacia las anfitrionas», «Sobre la carne de cordero», «Sobre los cumpleaños y los regalos de cumpleaños», «La ostra de un epicúreo», «Los domingos y las familias», «Sobre el tratamiento hacia las señoritas jóvenes», «Sobre la caza», «Exquisiteces», «El día del alcalde», «El concejal y sus hermanos los concejales», «Las navidades del concejal», «El pudding de navidad», «Paseos gastronómicos por Londres». Ibidem, pp. 5-95. 
mesocrático racional y utilitario de más calado que lo que era común en la tradición aristocrática de la gastronomía francesa. En particular, la reivindicación de una tradición culinaria británica - pese a las imitaciones casi serviles de los recetarios franceses - fue adquiriendo un peso cada vez mayor con el paso del tiempo, alimentada por el orgullo ante los asados locales o por las críticas al derroche y desperdicio de las complejas elaboraciones continentales. Como resultado de una compleja simbiosis entre el ideario de la última Ilustración dieciochesca y la rebeldía y la experimentación propia del movimiento romántico, los escritos sobre cuestiones culinarias alimentaron una tradición literaria de factura compleja. Las disquisiciones gastronómicas aparecían contaminadas de componentes filosóficos, de ocasionales defensas del utilitarismo o de divagaciones estéticas. En ocasiones, el tono burgués de la clientela se transparentaba en un ideario gastronómico que defendía en restaurantes o banquetes valores como el del individualismo, la privacidad o la competencia en buena educación entre los comensales; además de defenderse la utilidad y la economía en las preparaciones culinarias o el orden de las cocinas. Tampoco fue ajena aquella literatura a la masculinización de la sociedad, que se agudizó desde principios del nuevo siglo, y que desplazó a las mujeres, antaño reinas de los salones dieciochescos y centro de las conversaciones inteligentes, a un papel residual o meramente decorativo en los nuevos códigos de los banquetes. Fruto del nuevo espíritu romántico, en fin, los gastrónomos de principios del siglo XIX discutían el orden existente en distintos planos simbólicos; exhibiendo por ejemplo un humorismo desenfadado e iconoclasta; pero también contrariando el rigorismo moral de los movimientos por la «reforma de las costumbres» con su exhibición de la complacencia por el maltrato a los animales, o con el regodeo contumaz en los placeres de los sentidos. 